\title{
Animal Spirits and Fiscal Policy
}

\author{
Paul De Grauwe* \\ The London School of Economics and Political Science \\ Pasquale Foresti ${ }^{\diamond}$ \\ University of Roehampton \\ and \\ The London School of Economics and Political Science
}

\begin{abstract}
In this paper, we extend the behavioral macroeconomic model proposed by De Grauwe (2011) by including fiscal policy. In this model, agents have limited cognitive capabilities and use simple heuristics to forecast output and inflation. However, thanks to a learning mechanism, agents can revise their forecasting rule according to its performance. This feature produces endogenous and self-fulfilling waves of optimism and pessimism (animal spirits). This framework allows us to show that the short-run spending multiplier is state-dependent. The multiplier is stronger under either extreme optimism or pessimism and reduces in periods of tranquility. Furthermore, the more the central bank focuses on output stabilization, the smaller the multiplier. We also show that periods of increasing public debt are characterized by intense pessimism, while intense optimism occurs in periods of decreasing debt. This allows us to show that governments face a trade-off between the stabilization of the output gap and the stabilization of public debt. We also evaluate our model at the zero lower bound and find that the lower the inflation target, the more likely the system can be gripped in a deflationary spiral that is dynamically unstable and characterized by chronic pessimism and exploding public debt.
\end{abstract}

JEL Code: E10, E32, E62, E71, D83.

Keywords: Fiscal Policy, Spending Multiplier, Behavioral DSGE Model, Animal Spirits, Public Debt, Policy State-Dependent Effects.

\footnotetext{
*p.c.de-grauwe@lse.ac.uk.

○pasquale.foresti@roehampton.ac.uk,p.foresti@lse.ac.uk.
} 


\section{Introduction}

The global financial crisis and subsequent economic dynamics have revived the interest in the role of fiscal policy as a macroeconomic stabilization tool. As a result, empirical and theoretical studies have been aimed at improving our understanding of some aspects related to fiscal policy such as: what is the impact of government expenditure on the general level of economy activity, how to avoid public debt upsurge, and how to maneuver fiscal instruments over the business cycle.

Theoretical contributions have mainly relied on rational expectations DSGE models, in which the representative agent is able to understand the complexity of the underlying mathematical model. However, the global financial crisis has shown how agents do not fully understand the complexity of the world they live in. On the contrary, their cognitive capabilities seem to be very limited. This argument is strongly supported by the fact that empirical evidence of agents' heterogeneity and limited cognitive abilities has been provided by using both laboratory and survey data (see Carroll, 2003; Branch, 2004; Pfajfar and Santoro, 2010; Frenkel and Froot, 1987, 1988; Hommes, 2011). Still, researchers have started incorporating behavioral economics elements in dynamic macro models only recently (see Driscoll and Holden, 2014), and this is especially true in relation to fiscal policy (see Evans et al., 2009, 2012; Gasteiger and Shoujian, 2014; Caprioli, 2015; Gabaix, 2016). Furthermore, some contributions have highlighted how the linearity implied by rational expectations DSGE models makes them not fully suitable for fiscal policy analyses. The reason is that policies' state-dependency is, to a large extent, ruled-out in such models (see Parker, 2011; Auerbach and Gorodnichenko 2012).

Therefore, studying the role of fiscal policy by means of macroeconomic frameworks able to take into account the cognitive limitations of agents can provide additional insights. This is what we do in this paper. Building on De Grauwe (2011), we present a dynamic macroeconomic model in which both fiscal and monetary policies can be studied under the assumption that agents have bounded rationality and form their expectations based on simple heuristics. Following Brock and Hommes $(1997,1998)$, we treat the formation of expectations as being an interactive process between two types of agents. Fundamentalist agents forecast output and inflation based on their equilibrium and target values, respectively. The second type of agents use a simple forecasting rule based on extrapolating the last available observation of inflation and output. De Grauwe (2011) 
implements these heterogeneous expectations in a standard three-equation $\mathrm{New}$ Keynesian model and shows how such a framework is able to generate endogenous waves of optimism and pessimism (animal spirits) that are strongly linked with the business cycle. We extend this framework by adding fiscal variables and a fiscal policy block formed by a public spending rule and by an equation representing the evolution of public debt. Our framework generates very interesting results.

The model provides theoretical backgrounds for the uncertainty regarding the spending multiplier. It supports the evidence of expansionary (restrictive) short-run effects of an expenditure raise (cut), but it also shows how the value of the spending multiplier is volatile and state-dependent.

According to our results, the dimension of the spending multiplier depends on the timing of the fiscal policy, as its short-run effects change according to the state of expectations and animal spirits. The short-run multiplier is stronger under either extreme optimism or pessimism and is smaller in periods of tranquility. One policy implication is that austerity in periods of strong contraction will imply strong negative impact on output.

Furthermore, we show that the impact of a change in public spending also depends on the behavior of the central bank. An active role of the central bank in the stabilization of output will reduce the real effects of fiscal policy. The more the central bank focuses on output stabilization, the lower the short-run impact of government spending on output. However, the degree of the central bank's focus on output stabilization does not alter the general link between animal spirits and the spending multiplier, as the latter is stronger around, positive and negative, peaks in the animal spirits irrespective of monetary policy. Regarding the link between the fiscal stance and the level of public debt, our model confirms results in the literature concerning the required weight of debt stabilization in the fiscal rule in order to avoid disruptive debt dynamics. However, we show that, under common and reasonable calibrations of the fiscal rule, government spending is not able to reduce the presence of animal spirits even assuming strong focus on output stabilization. In order to be able to eliminate the presence of animal spirits, the fiscal authority should give up debt stabilization. We show that this result arises from the fact that periods of increasing public debt are characterized by intense pessimism and periods of decreasing public debt are characterized by intense optimism. As a consequence, we 
also show that governments face a trade-off between the stabilization of the output gap and the stabilization of public debt.

Finally, we study the functioning of our model in the presence of the zero lower bound (hereafter ZLB) on the nominal interest rate and show that the lower the inflation target, the more likely the system can be gripped in a deflationary spiral that is dynamically unstable and characterized by chronic pessimism and exploding public debt.

The paper is organized as follows. In Section 2, we present the equations of the model, explain the expectations formation, define the variable measuring animal spirits and discuss the calibration of the model. In Section 3, we analyze the basic characteristics of the model and explain the relations between animal spirits, output and inflation. In Section 4, we discuss the properties of the government spending multiplier in the long and short run. In Section 5, we investigate the links between public debt, output, animal spirits and the conduct of fiscal policy. In section 6, we evaluate the model at the ZLB. Section 7 concludes the paper.

\section{The Model}

We extend the behavioral model presented by De Grauwe (2011). By adding a fiscal policy block, we can then study the role of public expenditure in a dynamic model characterized by non-linearity.

\subsection{Basic Equations}

The model consists of an aggregate demand equation, an aggregate supply equation, a Taylor rule, a fiscal policy rule and an equation representing the evolution of public debt. To this aim, the usual linearized 3-equation New Keynesian block (see Galí, 2008) is modified by adding government spending $\left(g_{t}\right)$ as the instrument of fiscal policy. This allows us to write the first three equations of the model as follows:

$$
\begin{aligned}
& y_{t}=a_{1} \tilde{E}_{t} y_{t+1}+\left(1-a_{1}\right) y_{t-1}-a_{2}\left(r_{t}-\tilde{E}_{t} \pi_{t+1}\right)+a_{3} g_{t}+\epsilon_{t} \\
& \pi_{t}=b_{1} \tilde{E}_{t} \pi_{t+1}+\left(1-b_{1}\right) \pi_{t-1}+b_{2} y_{t}-b_{3} g_{t}+\eta_{t}
\end{aligned}
$$




$$
r_{t}=c_{1}\left(\pi_{t}-\pi^{*}\right)+c_{2} y_{t}+c_{3} r_{t-1}+\mu_{t}
$$

Equation (1) represents the aggregate demand, in which $y_{t}$ is the output gap in period $t$, $r_{t}$ is the nominal interest rate, $\pi_{t}$ is the rate of inflation and $g_{t}$ is public expenditure (as a percent of GDP). $\tilde{E}_{t}$ represents the expectations and the tilde above $E$ refers to the fact that expectations are not formed rationally. The way in which these expectations are formed will be specified in sections 2.2 and 2.3. We follow the procedure introduced in New Keynesian DSGE models of adding lagged output in the demand equation. This can be justified by invoking inertia in decision-making due to habit formation and institutional constraints. Given equation (1), a fiscal expansion at time $t$ increases $y_{t}$ via $a_{3}$.

Equation (2) represents the aggregate supply in the form of a New Keynesian Phillips Curve, in which current inflation depends on both a forward-looking component, $\widetilde{E}_{t} \pi_{t+1}$, and lagged inflation. Inflation at time $t$ also depends on the output gap and reacts to changes in public expenditure. The negative effect of government spending on inflation is explained in the literature by arguing that, following an increase in public spending, firms reduce the mark-up to meet the extra demand at the given prices (see Monacelli and Perotti, 2008) ${ }^{1}$. Then, the reduction in the mark-up implies lower inflation. At the same time, there is an indirect positive effect of $g_{t}$ on $\pi_{t}$ operating via the changes in output $\left(a_{3} \cdot b_{2}\right)$.

Equation (3) represents the Taylor rule followed by the central bank, in which $\pi^{*}$ is the inflation target. Hence, the central bank is assumed to raise the interest rate (its policy instrument) when the observed inflation rate increases relative to the announced target. The intensity of the monetary authority's reaction is measured by the coefficient $c_{1}$. This parameter is important as it has been shown that it must exceed 1 for the model to be stable. This is also sometimes called the "Taylor principle" (see Galí, 2008). When the output gap increases, the central bank is assumed to raise the interest rate. The intensity of this increase is measured by $c_{2}$. The latter parameter also tells us something about the ambitions of the central bank regarding output stabilization, as a central bank that does

\footnotetext{
${ }^{1}$ Other contributions justify the counter-cyclicality of the mark-up by introducing good-specific habits (see for instance Ravn et al., 2006).
} 
not care about output stabilization sets $c_{2}=0$. Finally note that, as is commonly done in the literature, the central bank is assumed to smooth the interest rate. This smoothing behavior is represented by the lagged interest rate, $r_{\mathrm{t}-1}$, in equation (3).

We have added error terms in each of the three equations. These error terms represent demand shocks $\left(\epsilon_{t}\right)$, supply shocks $\left(\eta_{t}\right)$ and monetary policy shocks $\left(\mu_{t}\right)$, respectively. These shocks are assumed to be normally distributed with zero mean and constant standard deviation.

Having included $g_{t}$ in the 3-equation New Keynesian block allows us to add a fiscal policy block.

The fiscal policy rule assumes that the government pursues three objectives: it smooths public expenditure, it aims at stabilizing the business cycle and it wishes to stabilize the level of public debt $\left(d_{t}\right)$ :

$$
g_{t}=f_{1} g_{t-1}-f_{2} y_{t-1}-f_{3} d_{t}+v_{t}
$$

Equation (4) assumes one lag in the reaction of fiscal policy to the output gap (see Muscatelli and Tirelli, 2005) and $f_{2}$ measures the intensity of such reaction. The parameter $f_{3}$ measures the government's focus on debt stabilization. Fiscal policy shocks $\left(v_{t}\right)$ are introduced in equation (4) and are assumed to be normally distributed with constant standard deviation.

The model is completed by a linearized version of the equation representing the evolution of public debt (the government's solvency constraint). In this respect, we follow Kirsanova et al. (2007) and assume that the government buys goods and services $(G)$, taxes income at a constant rate $(\tau)$ and issues nominal debt $(D)$. Thus, we can write the evolution of debt according to its standard equation: $D_{t+1}=\left(1+r_{t}\right)\left(D_{t}+G_{t} P_{t}-\tau Y_{t} P_{t}\right)$. By defining $d_{t}=D_{t} / P_{t-1}$, the linearized version of the equation is (see Kirsanova et al., 2007; Kirsanova and Wren-Lewis, 2012):

$$
d_{t+1}=r_{t}+(1+r)\left(d_{t}-\pi_{t}+h_{1} g_{t}-h_{2} \tau y_{t}\right)+\varphi_{t}
$$


In this specification $r$ is the interest rate in the steady state, while $\tau$ represents the constant income tax rate. Thus, although our model assumes that fiscal policy is performed only via government spending, taxation is still included in the form of automatic stabilizer. As all the other shocks, also public debt shocks $\left(\varphi_{t}\right)$ are assumed to be normally distributed with constant standard deviation.

\subsection{Expectations: Heuristics in Forecasting Output}

Under rational expectations, agents are assumed to have superior cognitive abilities allowing them to understand the complexity of the world they live in.

In this article, we depart from this approach and take the view that agents have limited cognitive capabilities and use simple rules, heuristics, when forming their expectations as in De Grauwe (2011). Specifically, we assume that agents can use two types of rules in order to forecast the output gap. This approach has been pioneered by Brock and Hommes (1998).

The first one is called a fundamentalist rule. According to this rule, agents use the steady state value of the output gap (which is normalized to 0 ) to forecast it.

The second rule is an extrapolative one. By following this rule, agents extrapolate the previous observed output gap into the future. The two rules are specified as follows:

$$
\begin{aligned}
& \tilde{E}_{t}^{f} y_{t+1}=y^{*}=0 \\
& \tilde{E}_{t}^{e} y_{t+1}=y_{t-1}
\end{aligned}
$$

The market forecast of the output gap is then obtained as the weighted average of the two heuristics:

$$
\tilde{E}_{t} y_{t+1}=\alpha_{f, t} \tilde{E}_{t}^{f} y_{t+1}+\alpha_{e, t} \tilde{E}_{t}^{e} y_{t+1}
$$

Where $\alpha_{f, t}$ and $\alpha_{e, t}$ are the probabilities that agents use a fundamentalist or an extrapolative rule and then $\alpha_{f, t}+\alpha_{e, t}=1$. Clearly, $\alpha_{f, t}$ and $\alpha_{e, t}$ also represent the fractions of agents using the fundamentalist and extrapolative rules, respectively. 
Although agents employ simple rules, this does not mean that they are irrational. In our model, rationality is intended by the fact that agents are willing to learn from their errors. Thus, we specify a learning mechanism by which agents continuously try to correct for their errors by switching from one rule to the other.

The performance of the two forecasting rules is measured as follows:

$$
\begin{aligned}
& U_{f, t}=-\sum_{k=0}^{\infty} \omega_{k}\left(y_{t-k-1}-\tilde{E}_{t-k-2}^{f} y_{t-k-1}\right)^{2} \\
& U_{e, t}=-\sum_{k=0}^{\infty} \omega_{k}\left(y_{t-k-1}-\tilde{E}_{t-k-2}^{e} y_{t-k-1}\right)^{2}
\end{aligned}
$$

Where $U_{f, t}$ and $U_{e, t}$ represent the utilities (performance) of the fundamentalist and extrapolative rules as based on the mean squared forecasting errors (MSFEs) of their predictions; $\omega_{k}$ are the weights assigned to each forecast error in time. We make these weights declining because we assume that agents tend to forget and give a lower weight to errors made far in the past as compared to errors made recently. Hence, we specify these weights as geometrically declining and define $\omega_{k}=(1-\rho) \rho^{k}$, with $0 \leq \rho \leq 1$. Under this specification of the weights, equations (9) and (10) can be rewritten as:

$$
\begin{aligned}
& U_{f, t}=\rho U_{f, t-1}-(1-\rho)\left(y_{t-1}-\tilde{E}_{t-2}^{f} y_{t-1}\right)^{2} \\
& U_{e, t}=\rho U_{e, t-1}-(1-\rho)\left(y_{t-1}-\tilde{E}_{t-2}^{e} y_{t-1}\right)^{2}
\end{aligned}
$$

We can interpret $\rho$ as the measure of agents' memory. When $\rho=0$ there is no memory as $U_{f, t}=-\left(y_{t-1}-\tilde{E}_{t-2}^{f} y_{t-1}\right)^{2}$ and $U_{e, t}=-\left(y_{t-1}-\tilde{E}_{t-2}^{e} y_{t-1}\right)^{2}$. Thus, only the last period is used to measure the performance of the heuristics. On the contrary, with $\rho=1$ there is infinite memory because $U_{f, t}=U_{f, t-1}$ and $U_{e, t}=U_{e, t-1}$.

As a further step, we need to specify how agents evaluate the utilities of the rules. In this respect, we apply discrete choice theory (see Anderson et al., 1992; and Brock and Hommes, 1997). If agents were purely rational, they would just compare $U_{f, t}$ and $U_{e, t}$ in (9) and (10) and choose the rule that produces the highest utility. Thus, under pure rationality, agents would choose the fundamentalist rule if $U_{f, t}>U_{e, t}$ and vice versa. However, psychologists have stressed that when we have to choose among alternatives, 
we are also influenced by our state of mind (see Kahneman, 2002). The latter is, to a large extent, unpredictable as it can be influenced by many elements (weather, recent emotional experiences, etc). One way to formalize this is to assume that the utilities of the two alternative rules have a deterministic component ( $U_{f, t}$ and $U_{e, t}$ as represented in (9) and (10)) and a random component $\varepsilon_{f, t}$ and $\varepsilon_{e, t}$. Thus, the probability of choosing the fundamentalist rule is given by:

$$
\alpha_{f, t}=\mathrm{P}\left[U_{f, t}+\varepsilon_{f, t}>U_{e, t}+\varepsilon_{e, t}\right]
$$

This means that the probability of selecting the fundamentalist rule is equal to the probability that the stochastic utility associated with using this rule exceeds the stochastic utility of using the extrapolative rule.

In order to derive a more precise expression, we have to specify the distribution of the random variables $\varepsilon f, t$ and $\varepsilon_{e, t}$. Assuming that they are logistically distributed (see Anderson et al., 1992; Manski and McFadden, 1981), we obtain the following expressions for the probability of choosing the fundamentalist rule:

$$
\alpha_{f, t}=\frac{\exp \left(\gamma U_{f, t}\right)}{\exp \left(\gamma U_{f, t}\right)+\exp \left(\gamma U_{e, t}\right)}
$$

Similarly, the probability that an agent will use the extrapolative forecasting rule is:

$$
\alpha_{e, t}=\frac{\exp \left(\gamma U_{e, t}\right)}{\exp \left(\gamma U_{f, t}\right)+\exp \left(\gamma U_{e, t}\right)}=1-\alpha_{f, t}
$$

Equation (14) shows that as the past forecast performance of the fundamentalist rule improves relative to that of the extrapolative one, agents are more likely to select the fundamentalist rule for their forecasts of the output gap. As $\alpha_{f, t}$ and $\alpha_{e, t}$ also represent the fractions of agents using the fundamentalist and extrapolative rules, equations (14) and (15) show how these fractions are time dependent. This is the most important feature of the model, because it implies that the number of agents using the two rules is not constant and changes according to the utility (performance) of these rules. Hence, $\alpha_{f, t}$ and $\alpha_{e, t}$ change over time and such changes are endogenously generated within the 
model. According to equations (14) and (15), the distribution of agents in the two categories is also determined by the parameter $\gamma$. This parameter measures the agents' willingness to learn (intensity of choice) and it is related to the variance of the random components in (13). When the variance goes to infinity, $\gamma$ approaches 0 . In that case agents decide to be fundamentalist or extrapolator by tossing a coin and the probability to be fundamentalist (or extrapolator) is exactly 0.5 . Therefore, in this case agents do not learn from past mistakes. As $\gamma$ increases, agents become more sensitive to the past performance of the rules they use and then are more willing to learn from past errors (see De Grauwe, 2012). When $\gamma=\infty$, the variance of the random components is zero (the measure of the rule performance is then fully deterministic) and the probability of using a fundamentalist rule is either 1 or 0 .

Thus, the selection mechanism that we employ should be interpreted as a learning mechanism based on "trial and error". When agents observe that the rule they use performs less well than the alternative one, they are willing to switch to the more performing rule. Put differently, agents avoid making systematic mistakes by constantly being willing to learn from past mistakes and to change their behavior.

\subsection{Expectations: Heuristics in Forecasting Inflation}

The expectations on inflation follow the same logic applied to the output gap. Also for inflation, agents are assumed to switch between a fundamentalist and an extrapolative rule. However, when the central bank explicitly announces its inflation target, inflation fundamentalists are assumed to base their expectations on the central bank's target $\left(\pi^{*}\right)$. Therefore, we define this rule as inflation targeting and the agents adopting it as targeters. By contrast, inflation extrapolators behave exactly as output gap extrapolators do: by naively forecasting inflation based on the last available observation of inflation. Also the inflation forecast is obtained as a weighted average of these two rules:

$$
\tilde{E}_{t} \pi_{t+1}=\beta_{t a r, t} \tilde{E}_{t}^{t a r} \pi_{t+1}+\beta_{\text {ext }, t} \tilde{E}_{t}^{e x t} \pi_{t+1}
$$


With $\tilde{E}_{t}^{t a r} \pi_{t+1}=\pi^{*}=0$ and $\tilde{E}_{t}^{e x t} \pi_{t+1}=\pi_{t-1}$ representing the targeting and extrapolative inflation expectations, respectively. Also in this case, $\beta_{t a r, t}$ and $\beta_{\text {ext }, t}$ are the fractions of agents using the two rules and therefore $\beta_{\text {tar }, t}+\beta_{\text {ext }, t}=1$.

As we apply to inflation forecasts the same selection mechanism used in the case of output, we can express the fractions of agents using the two rules as follows:

$$
\begin{aligned}
& \beta_{\text {tar }, t}=\frac{\exp \left(\gamma U_{t a r, t}\right)}{\exp \left(\gamma U_{t a r}, t\right)+\exp \left(\gamma U_{\text {ext }, t}\right)} \\
& \beta_{\operatorname{ext}, t}=\frac{\exp \left(\gamma U_{\text {ext }, t}\right)}{\exp \left(\gamma U_{t a r, t}\right)+\exp \left(\gamma U_{\text {ext }, t}\right)}
\end{aligned}
$$

Where $U_{t a r, t}$ and $U_{\text {ext,t }}$ measure the forecast performance of using the targeting and extrapolative rules and are defined in the same way as in (9) and (10). Therefore, also the selection of the forecasting rule for inflation is based on adaptive learning, with $\beta_{t a r, t}$ and $\beta_{\text {ext }, t}$ changing over time according to the performance of their respective rules.

\subsection{Defining Animal Spirits}

Our model allows us to define an index of market sentiments, which we call animal spirits, reflecting how optimistic or pessimistic these forecasts are. We define animal spirits as:

$$
S_{t}=\left\{\begin{array}{ccc}
\alpha_{e, t}-\alpha_{f, t} & \text { if } & y_{t-1}>0 \\
-\alpha_{e, t}+\alpha_{f, t} & \text { if } & y_{t-1}<0
\end{array}\right.
$$

Hence, the index of animal spirits ranges between -1 (maximum level of pessimism) and +1 (maximum level of optimism). The index considers two possibilities depending on the sign of $y_{t-1}$.

When $y_{t-1}>0$, extrapolators forecast a positive output gap. The fraction of agents who make such a positive forecasts is $\alpha_{e, t}$. On the contrary, under the same circumstance, fundamentalists make a pessimistic forecast since they expect the positive output gap to decline towards the equilibrium value of 0 . The fraction of agents who make such a forecast is $\alpha_{f, t}$. We subtract this fraction of pessimistic forecasts $\left(\alpha_{f, t}\right)$ from the fraction of agents making a positive forecast $\left(\alpha_{e, t}\right)$. When these two fractions are equal (both are 
then 0.5 ) market sentiments are neutral, i.e. optimists and pessimists cancel out and $S_{t}=0$. When the fraction of optimists $\alpha_{e, t}$ exceeds the fraction of pessimists $\alpha_{f, t}, S_{t}$ becomes positive. As we will see, the model allows for the possibility that $\alpha_{e, t}=1$. In that case there are only optimists and $S_{t}=1$.

When $y_{t-1}<0$, extrapolators forecast a negative output gap. The fraction of agents making such negative forecasts is $\alpha_{e, t}$. We give this fraction a negative sign. At the same time, fundamentalists make an optimistic forecast when $y_{t-1}<0$, because they expect the negative output gap to increase towards the equilibrium value of 0 . The fraction of agents making such a forecast is $\alpha_{f, t}$. We give this fraction of optimistic forecasts a positive sign. Again, market sentiments are neutral when these two fractions are equal, i.e. optimists and pessimists cancel out and $S_{t}=0$. When the fraction of pessimists, $\alpha_{e, t}$, exceeds the fraction of optimists $\alpha_{f, t}$, St becomes negative. When $\alpha_{e, t}=1$, there are only pessimists and $S_{t}=-1$.

Given that $\alpha_{f, t}+\alpha_{e, t}=1$, we can re-write equation (19) as:

$$
S_{t}=\left\{\begin{array}{l}
\alpha_{e, t}-\left(1-\alpha_{e, t}\right)=2 \alpha_{e, t}-1 \quad \text { if } \quad y_{t-1}>0 \\
-\alpha_{e, t}+\left(1-\alpha_{e, t}\right)=-2 \alpha_{e, t}+1 \quad \text { if } \quad y_{t-1}<0
\end{array}\right.
$$

\subsection{Calibration}

The model has non-linear features, making it difficult to arrive at analytical solutions. Thus, we will use numerical methods to analyze its dynamics.

To this aim, we have to calibrate the model. Table 1 presents the values used in the calibration exercise, together with references to articles where single parameters are calibrated like in our study.

It is worth noting that the calibration of equation (5) has been conducted by assuming a debt to GDP ratio of $60 \%$ in the steady state, and a $4 \%$ yearly risk free return (these are common practice in the literature ${ }^{2}$ ). The five shocks (demand, supply, interest rate, public expenditure and public debt shocks) are independently and identically distributed, with zero mean and constant standard deviation equal to 0.5 (see De Grauwe, 2012).

\footnotetext{
2 See Ferrero (2009), Kirsanova et al. (2015) and (2017) and Kirsanova and Wren-Lewis (2012).
} 
Table 1: Calibrated Parameters of the Model

\begin{tabular}{|c|c|}
\hline $\mathrm{a}_{1}=0.5$ & Coefficient of expected output in output equation ${ }^{\mathrm{Y}}$ \\
\hline $\mathrm{a}_{2}=0.2$ & Interest elasticity of output equation ${ }^{\mathrm{X}}$ \\
\hline $\mathrm{a}_{3}=0.25$ & Coefficient of public expenditure in output equation ${ }^{\times, 3}$ \\
\hline $\mathrm{b}_{1}=0.5$ & Coefficient of expected inflation in inflation equation ${ }^{\searrow}$ \\
\hline $\mathrm{b}_{2}=0.05$ & Coefficient of output in inflation equation ${ }^{\mathrm{Y}}$ \\
\hline $\mathrm{b}_{3}=0.03$ & Coefficient of public expenditure in inflation equation ${ }^{\times}$ \\
\hline$c_{1}=1.5$ & Coefficient of inflation in Taylor rule ${ }^{\mathrm{X}}$ \\
\hline $\mathrm{c}_{2}=0.5$ & Coefficient of output in Taylor rule ${ }^{\gamma}$ \\
\hline$c_{3}=0.5$ & Interest smoothing parameter in Taylor rule* \\
\hline$\pi^{*}=0$ & Central bank's inflation target* \\
\hline $\mathrm{f}_{1}=0.6$ & Public expenditure smoothing in fiscal rule ${ }^{\complement}$ \\
\hline $\mathrm{f}_{2}=0.4$ & Coefficient of output in fiscal rule ${ }^{\mathrm{H}}$ \\
\hline $\mathrm{f}_{3}=0.03$ & Coefficient of public debt in fiscal rule ${ }^{\mathrm{H}}$ \\
\hline$r=0.01$ & S.S. interest rate ${ }^{\times, 3}$ \\
\hline $\mathrm{h}_{1}=0.4$ & Coefficient of public expenditure in debt equation ${ }^{\dagger}$ \\
\hline $\mathrm{h}_{2}=1.6$ & Coefficient of output in debt equation ${ }^{\dagger}$ \\
\hline$\tau=0.3$ & Income tax rate $\ddagger$ \\
\hline$\gamma=2$ & Intensity of choice parameter* \\
\hline$\rho=0.5$ & Memory parameter* \\
\hline \multicolumn{2}{|c|}{ 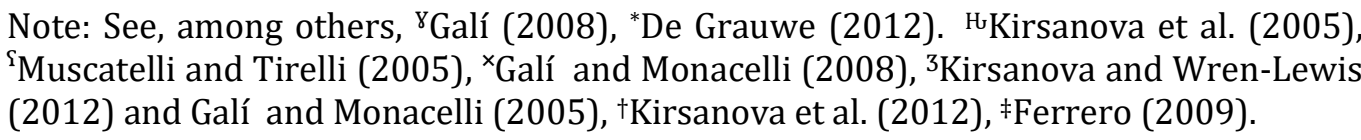 } \\
\hline
\end{tabular}

\section{Animal Spirits, Output and Inflation}

Figure 1 shows the movements of the output gap and animal spirits in the time domain (panel A) and in the frequency domain (panels B and C) as resulting from the simulation of our model ${ }^{5}$. Panel A shows a strong cyclical movement of the output gap in which the autocorrelation coefficient is $0.96^{6}$. Panels A and C allow us to confirm that the model

\footnotetext{
${ }^{5}$ Note that the calibrated model was simulated for 2000 periods but, for the sake of clarity, in panel A we show the results from period 1000 to 1350 . However, the full series do not differ from the results reported in this section. The same applies to figure 2 .

${ }^{6}$ This value is very close to the one reported in De Grauwe (2012) for the U.S.A. between 1960 and 2009.
} 
produces waves of optimism and pessimism (animal spirits) that can lead to a situation where everybody becomes optimist $\left(S_{t}=1\right)$ or pessimist $\left(S_{t}=-1\right)$.

Figure 1: Output and Animal Spirits

[A]

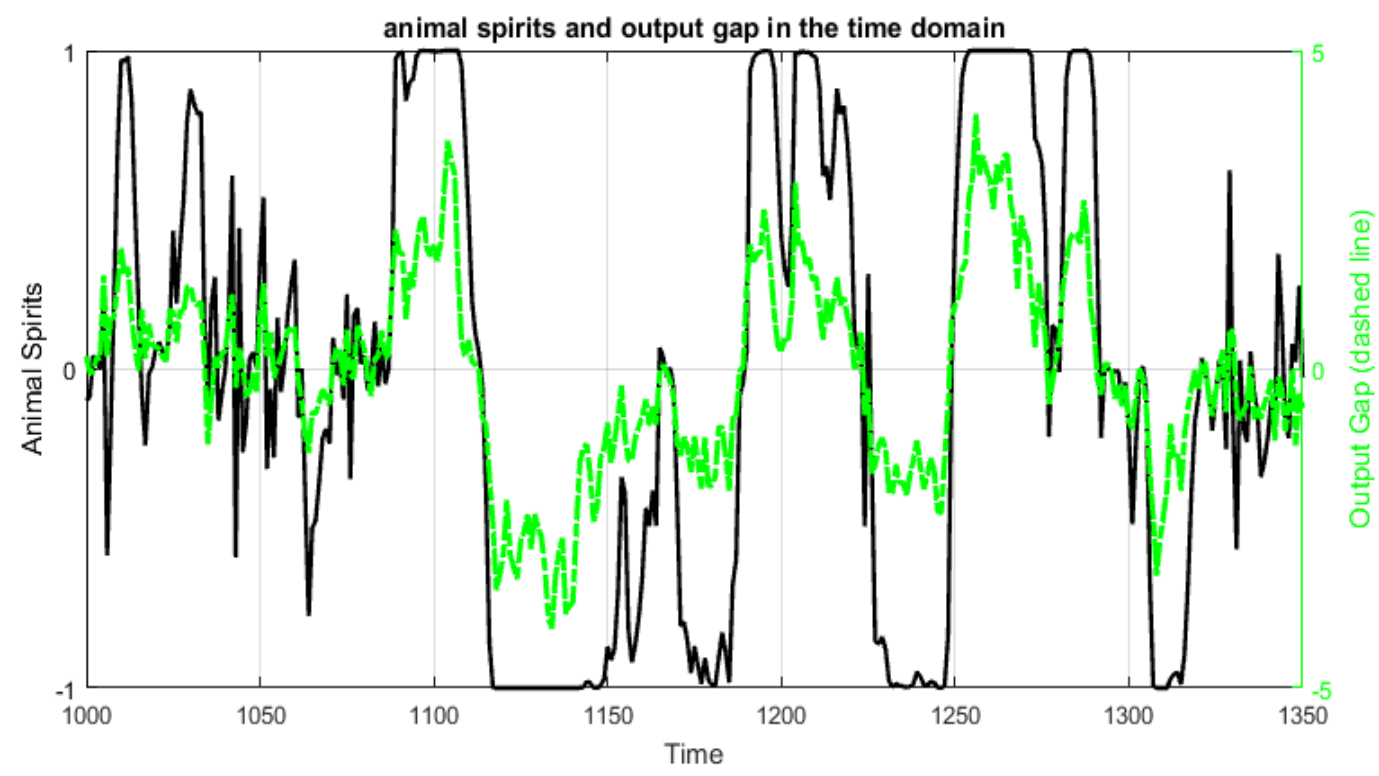

[B]

[C]
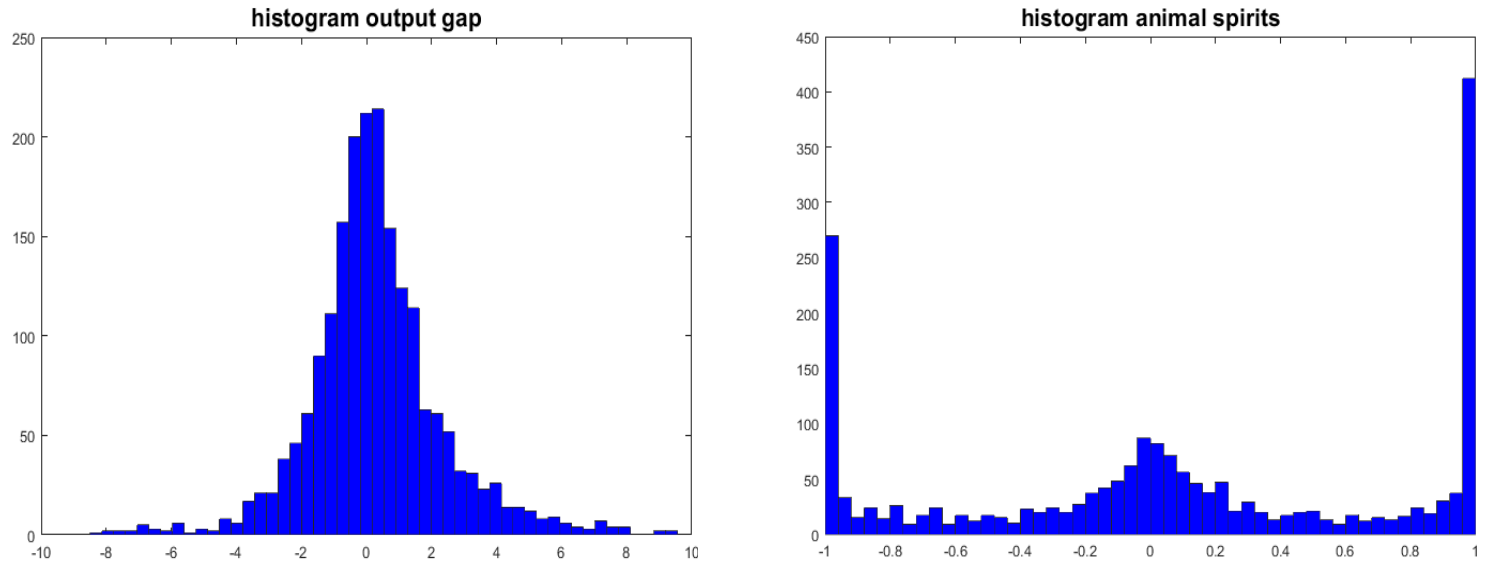

From panel A, we can conclude that the output gap is highly correlated with animal spirits. According to our simulation, the correlation between animal spirits and output gap is +0.85 . When optimists dominate, this translates into above average output gap. Such periods are then followed by pessimistic ones, where pessimist agents dominate and the output gap is below average. These waves of optimism and pessimism are 
generated endogenously. They arise because optimistic (pessimistic) forecasts are selffulfilling and therefore attract more agents into being optimist (pessimist) 7 .

The self-fulfilling mechanism is generated by the set of equations representing the expectations formation in the model and it can be explained as follows. A series of random shocks creates the possibility that one of the forecasting rules (e.g., the extrapolative one) has a higher performance. This will induce some fundamentalist agents to switch to the extrapolative forecasting rule. If the successful extrapolation refers to positive output gap, more agents will start to extrapolate a positive output gap. This will result in a contagion effect leading to an increase in the use of the optimistic extrapolation of the output gap. This stimulates aggregate demand (see equation (1)) and a boom is created. The increase in the aggregate demand leads to a situation in which those who have made optimistic forecasts are vindicated. This attracts more agents using optimistic forecasts and leads to a self-fulfilling dynamics in which most agents become optimists. The same logic can be applied to explain a bust.

We present the frequency distribution of the output gap in panel B of figure 1. First, we find that the output gap is not normally distributed, with excess kurtosis (in this case kurtosis is 5.64) and fat tails. Moreover, the Jarque-Brera test rejects normality of the distribution of the output gap. It is worth noting that the stochastic shocks in the model are all i.i.d., thus the non-normality of the distribution of the output gap is generated by the model itself. This contrasts with standard linear DSGE models that are only able to produce non-normal movements in output by introducing non-normally distributed shocks.

We obtain more insights on this mechanism by also looking at the frequency distribution of animal spirits in panel C of figure 1. Panel C shows how, in our model, the origin of the non-normality of the distribution of the output gap can be found in the distribution of the animal spirits. We can see that there is a concentration of observations at the extreme values of +1 (everybody is optimist) and -1 (everybody is pessimist) with a substantial amount of periods of tranquility in which animal spirits are around 0 (neither optimism nor pessimism prevail). These extreme values of animal spirits explain the fat tails

\footnotetext{
${ }^{7}$ The turnaround between the waves of optimism and pessimism can arise due to several factors, including shocks and policy interventions.
} 
observed in the distribution of the output gap. The interpretation of this result resides, again, in the nature of the expectations. When the market is gripped in a self-fulfilling movement of optimism (or pessimism), this can lead to a situation where everybody becomes optimist (pessimist). Therefore, movements in waves of optimism and pessimism characterize the dynamics of animal spirits and this also leads to intense booms and busts in economic activity.

In De Grauwe (2012) empirical evidence is provided indicating that observed output gap in industrial countries exhibits non-normality (due to fat tails and excess kurtosis) and that the output gap is highly correlated with empirical measures of animal spirits. Our model mimics these empirical observations and is particularly suited to understand the nature of the business cycle characterized by periods of tranquility alternated by periods of booms and busts.

In figure 2, we also present the simulated time path of the inflation rate and the fraction of agents using the extrapolative rule to predict the inflation. According to figure 2, we can identify two regimes in the link between the expectations formation and the inflation rate.

Figure 2: Inflation and Expectations

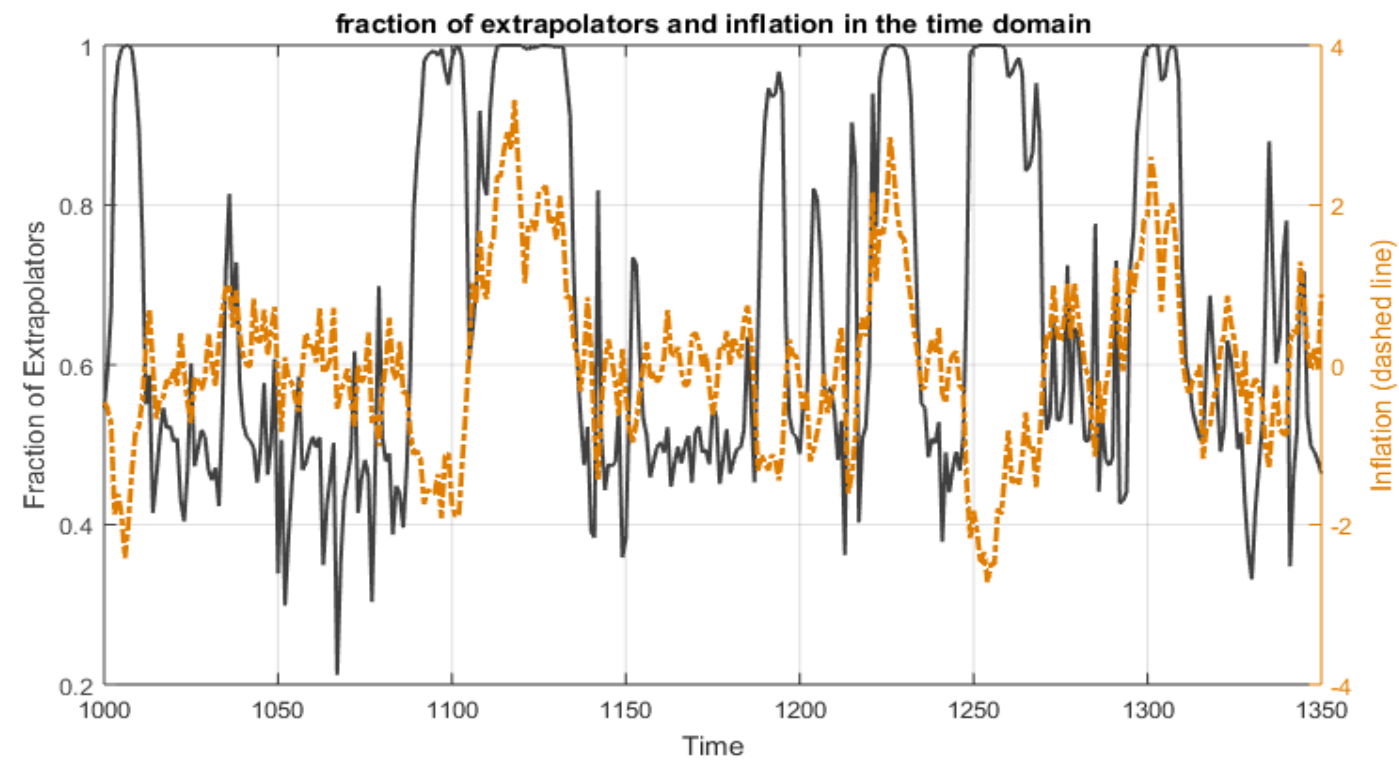


The simulated series show that agents tend to use the extrapolative rule when the inflation rate deviates from the central bank's target by around $\pm 2 \%$ or more. Conversely, when the observed inflation rate is around the target of the monetary authority, more agents tend to form their inflation forecasts based on the central bank's declared target.

\section{Real Effects of Government Spending}

The next step in our analysis is to investigate how shocks are transmitted in the economy by performing an impulse response analysis. In our model, impulse response functions (hereafter IRFs) are obtained by simulating two series of the endogenous variables: one is the series without the shock (baseline series) and the other is the series with the shock. Then, the IRF can be obtained by subtracting the former series from the latter. The IRF is then standardized by dividing it by the shock itself. The shocks are one standard deviation of the random disturbances in equations (1), (2), (3), (4) and (5).

Since we employ a non-linear model, during the post-shock period we continue to allow for random disturbances. Thus, the IRFs measure the response to the shock in an environment in which the random disturbances are the same for the series with and without the shock. The peculiarity of our behavioral model is that, for the same parameters of the model, the IRFs are different for each realization of the stochastic shocks. This contrasts with rational expectations models where the IRFs are not sensitive to the realization of the stochastic shocks.

Due to these features of the model, we present the average IRFs. For each IRF, the model has been simulated 1000 times with 1000 different realizations of the shocks, and then the mean response and the standard deviations have been computed. We have introduced the shocks after 100 periods in order to allow the system to converge to its ergodic distribution. In what follows, we will focus on the main aspects related to fiscal policy.

Figure 3, panel A, shows the mean response of the output gap following a positive expenditure shock (the dashed lines are the mean response + and -2 standard deviations). The IRF shows that an expansionary fiscal policy has a positive instantaneous effect on output that declines and slightly undershoots before dissipating. 


\section{Figure 3: Effects of Government Spending}

[A]

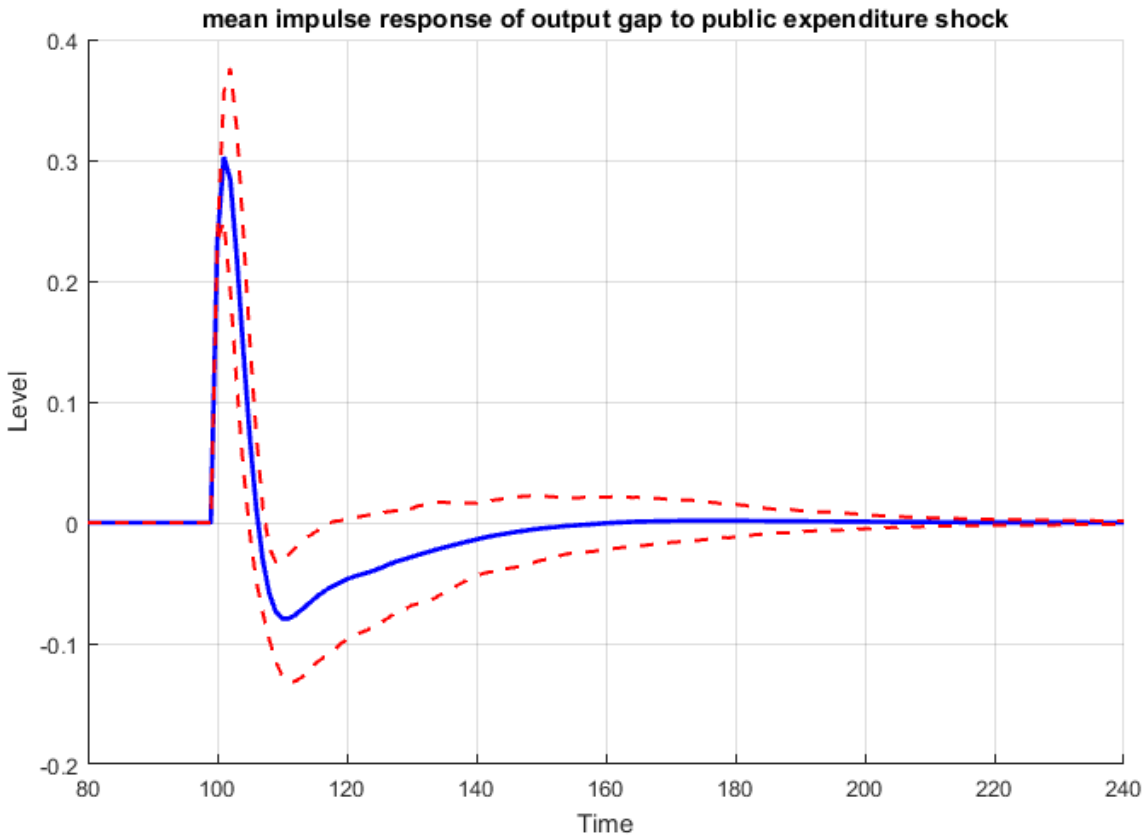

[B]

[C]

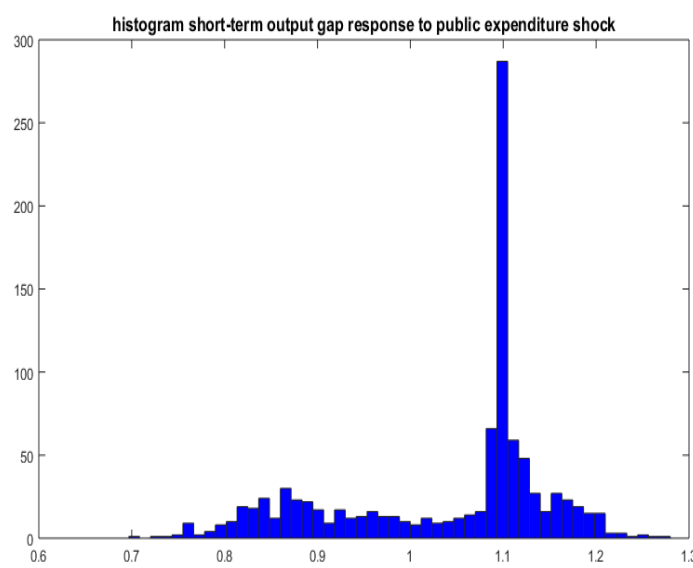

[D]

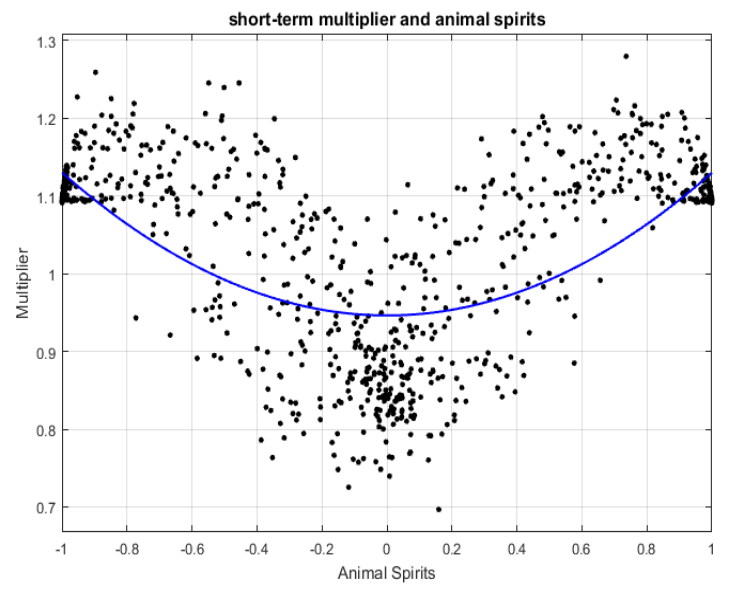

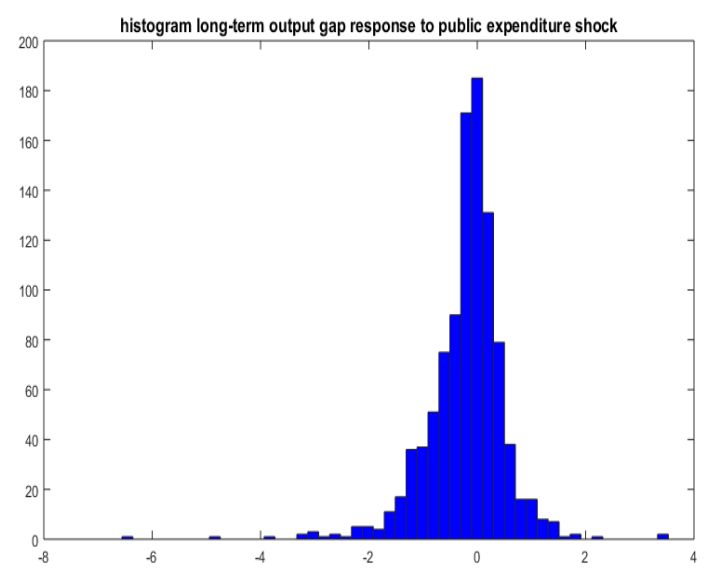

[E]

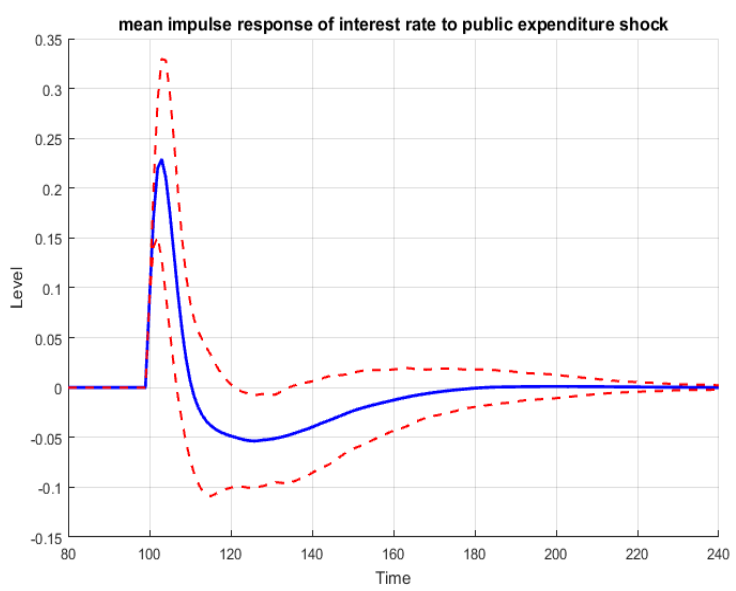


An important insight suggested by the figure is that there is a considerable level of uncertainty surrounding the real effects of fiscal policy. This can be easily verified from the fact that the dashed lines are far from the mean IRF. Note that figure 3, panel A, also shows that the uncertainty about the response tends to disappear in the long run.

This uncertainty can also be illustrated by presenting the frequency distribution of the cumulated output gap reaction following the fiscal policy shock. In order to do so, we differentiate between the short- and long-term cumulative output reaction.

The short-run effect of fiscal policy is computed by cumulating the effects of the first 4 periods after the shock, while the long-run effect is the sum considering the entire IRF. Panels $\mathrm{B}$ and $\mathrm{C}$ of figure 3 confirm how uncertainty regarding the effects of an increase in public spending is particularly relevant in the short run. A short-run multiplier of 1.1 is the most recurrent across the 1000 simulations but, according to panel $\mathrm{B}$, it ranges between 0.7 and 1.3. In the long run, such uncertainty is less pronounced as the total effect tends to 0 . This is due to the fact that, according to equation 4 , the fiscal authority maintains a debt constraint.

Where does the uncertainty about the effects of fiscal policy come from? It does not come from parameters uncertainty because the values of the parameters are constant in the 1000 simulations used to obtain the average IRFs. The uncertainty is generated by the expectations formation process. In our behavioral model, each realization of the shocks creates different waves of optimism and pessimism. Thus, a fiscal shock that occurs in period 100 in one simulation happens under different realizations of the animal spirits than in another simulation. In addition, the fiscal shock itself affects market sentiments. As a result, the short-term effects of a public expenditure shock become volatile and, therefore, hard to predict.

Another way to interpret this result is to say that the timing of the shock is important and that the effects of fiscal policy are state-dependent. The same public spending policy, applied at different times, can have different short-term effects on output depending on the state of the animal spirits. To confirm this result, we show the importance of the animal spirits in panel D of figure 3. On the horizontal axis we plot the mean value of the animal spirits index up to the fourth period after the shock. On the vertical axis the cumulated reaction of the output to the fiscal policy shock, in the same period, is shown. Thus, this figure represents the relation between animal spirits and the short-run 
spending multiplier. From the figure, we can conclude that there is a link between animal spirits and the real effects of fiscal policy. The effect of a change in public expenditure is stronger in periods of extreme pessimism or optimism, while in periods of relative tranquility (animal spirits around 0) the lowest output reaction is observed.

These results highlight how the difference in the nature of uncertainty between our behavioral model and a rational expectations one has everything to do with the fact that the former has non-linear features while the latter is linear. Hence, the additional uncertainty produced by the behavioral model, i.e. the dependence of the IRFs on the state of the economy and animal spirits, is the outcome of its non-linearity.

There are other sources of the state-dependency of the multiplier. Hence, we also focus on how monetary policy affects the spending multiplier. In panel E of figure 3 we show how the monetary authority reacts to an increase in government spending by increasing the interest rate. This is the result of the fact that the fiscal stimulus affects output and moves inflation away from the central bank's target, triggering a reaction in its policy instrument. Thus, the central bank tends to reduce the effects of fiscal policy in the short run. This suggests that the more the central bank reacts to changes in the output gap, the lower the public spending multiplier. In order to confirm this insight, we also show how different values of the output parameter in the Taylor rule affect the fiscal policy multiplier. This is done in Figure 4 where we replicate the analysis reported in panel D of figure 3, allowing for different values of the output parameter, $c_{2}$, in the Taylor rule.

Figure 4 makes clear that a less active role of the central bank in the stabilization of output (a reduction in $c_{2}$ ) increases the effects of fiscal policy on the level of economic activity. This adds another dimension to the state-dependency of the fiscal multiplier, as it also changes according to the level of the central bank's activism ${ }^{9}$.

Finally, it is worth noting how figure 4 shows that the different configurations of the Taylor rule do not alter the link between animal spirits and the short-run multiplier, as the shape of the fitted line does not change across different specifications of the Taylor rule. The spending multiplier results to be always higher in periods of extreme optimism

\footnotetext{
${ }^{9}$ Figure 4 shows how the multiplier can go from a maximum of 1.7 , scored when $c_{2}=0$, to a minimum of 0.5 , obtained under the condition that $c_{2}=1$.
} 
or pessimism and scores lower values in the absence of animal spirits irrespective of the Taylor rule parameter for output stabilization.

\section{Figure 4: Short-Term Multiplier, Animal Spirits and Monetary Policy}

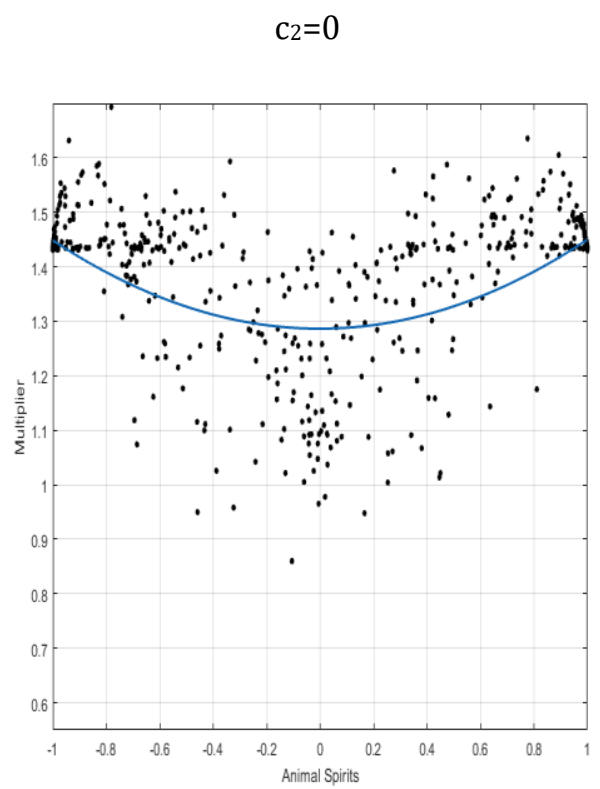

$\mathrm{C}_{2}=0.25$

$\mathrm{c}_{2}=0.75$
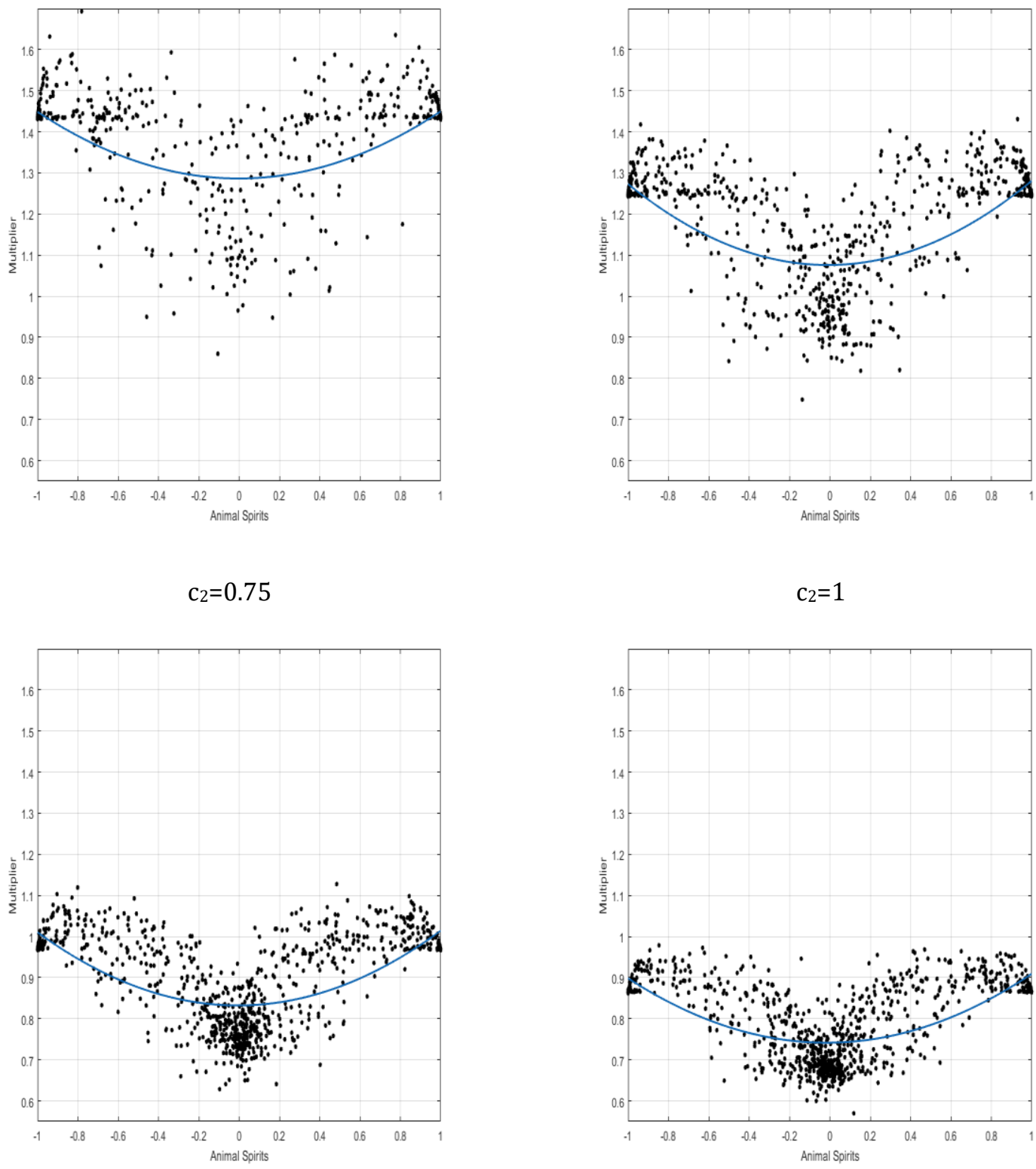

Given the strong correlation between animal spirits and the output gap (see figure 1 panel A), we can extend our results and say that the model also predicts that the spending multiplier is higher in both positive and negative peaks of the business cycle. Thus, one can conclude that countercyclical fiscal policies are likely to be very effective in smoothing the cycle around its (positive and negative) peaks. This also suggests that 
austerity measures during deep recessions are detrimental and are likely to intensify these recessions. The underlying reason for such result is that animal spirits amplify the effects of fiscal policy in periods of extreme optimism and pessimism.

\section{Fiscal Rule, Stabilization, Public Debt Dynamics and Animal Spirits}

In this section, we study how different configurations of the fiscal policy rule affect the behavior of the system. First, we focus on public debt stability ${ }^{10}$. In figure 5, we report the IRFs for public debt following a debt shock under different configurations of the debt parameter in the fiscal rule. We observe that when the parameter $f_{3}$ declines, it takes longer for the effects of the shock to disappear. Furthermore, three possible configurations guarantee the stabilization of debt, but with different timing. Among these, there is also our standard calibration of table $1\left(f_{3}=0.03\right)$. Figure 5 shows that when the debt parameter in the fiscal rule approaches the value of 0.005 public debt is dynamically unstable.

Figure 5: Debt Stabilization and Fiscal Rule

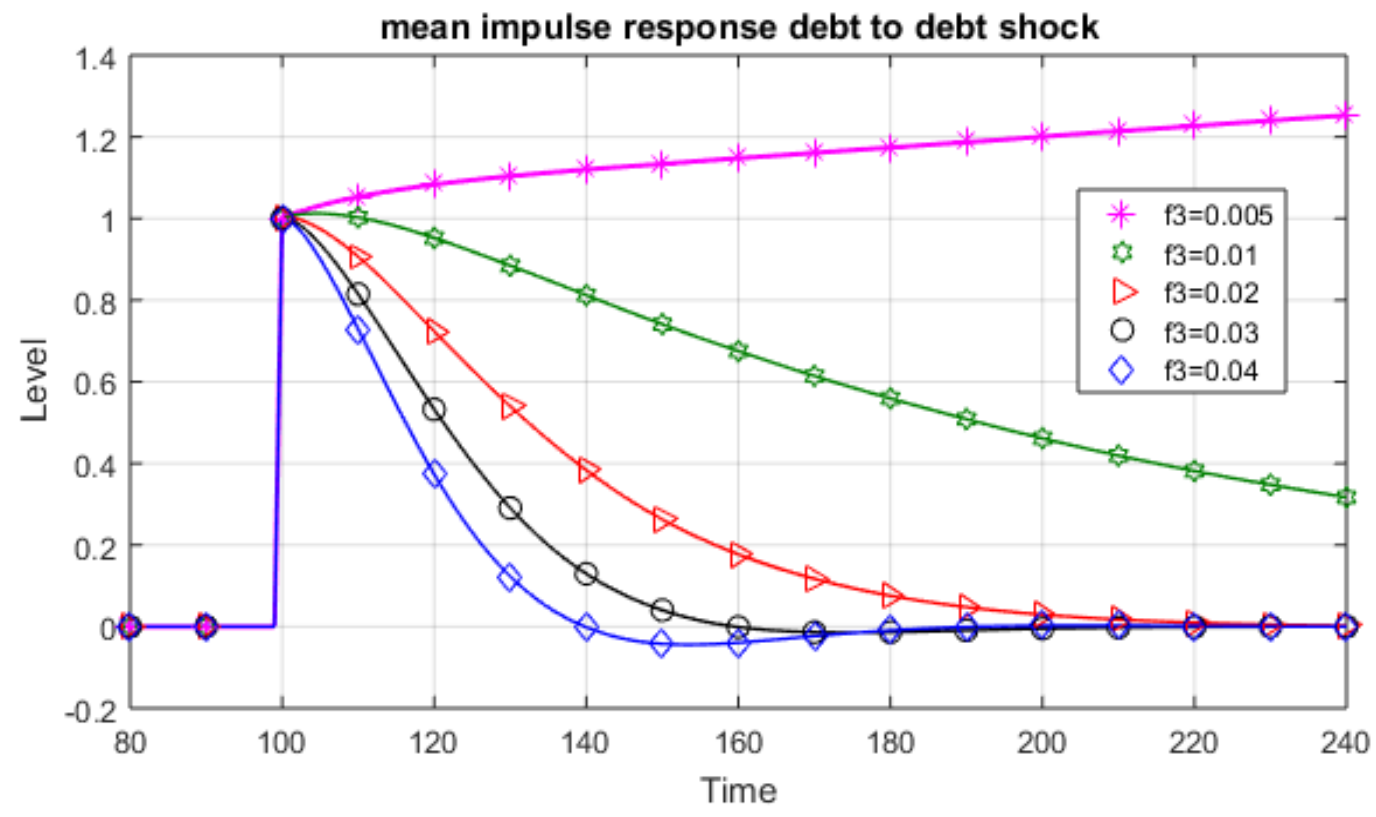

${ }^{10}$ A comparable exercise is done by Kirsanova et al. (2005) in a similar, although purely backward looking, 5 -equation model. They find that values of $f_{3}<0.01$ make it impossible to stabilize public debt. 
Hence, according to this sensitivity analysis, when the feedback coefficient on debt $\left(f_{3}\right)$ is too small, debt interest payments will cumulate making it very difficult to stabilize public debt.

After establishing how the fiscal authority can guarantee debt stability, we now investigate if fiscal policy can reduce the power of animal spirits and remove such a source of instability from the economy.

In order to shed light on this, we look at the frequency distribution of animal spirits for different values of the output parameter, $f_{2}$, in the government's fiscal policy rule. As shown in figure 6 , even very high values of $f_{2}$ do not substantially change the frequency distribution of animal spirits.

Figure 6: Animal Spirits under Different Output Coefficients in Fiscal Rule [With

\section{Debt Stabilization]}
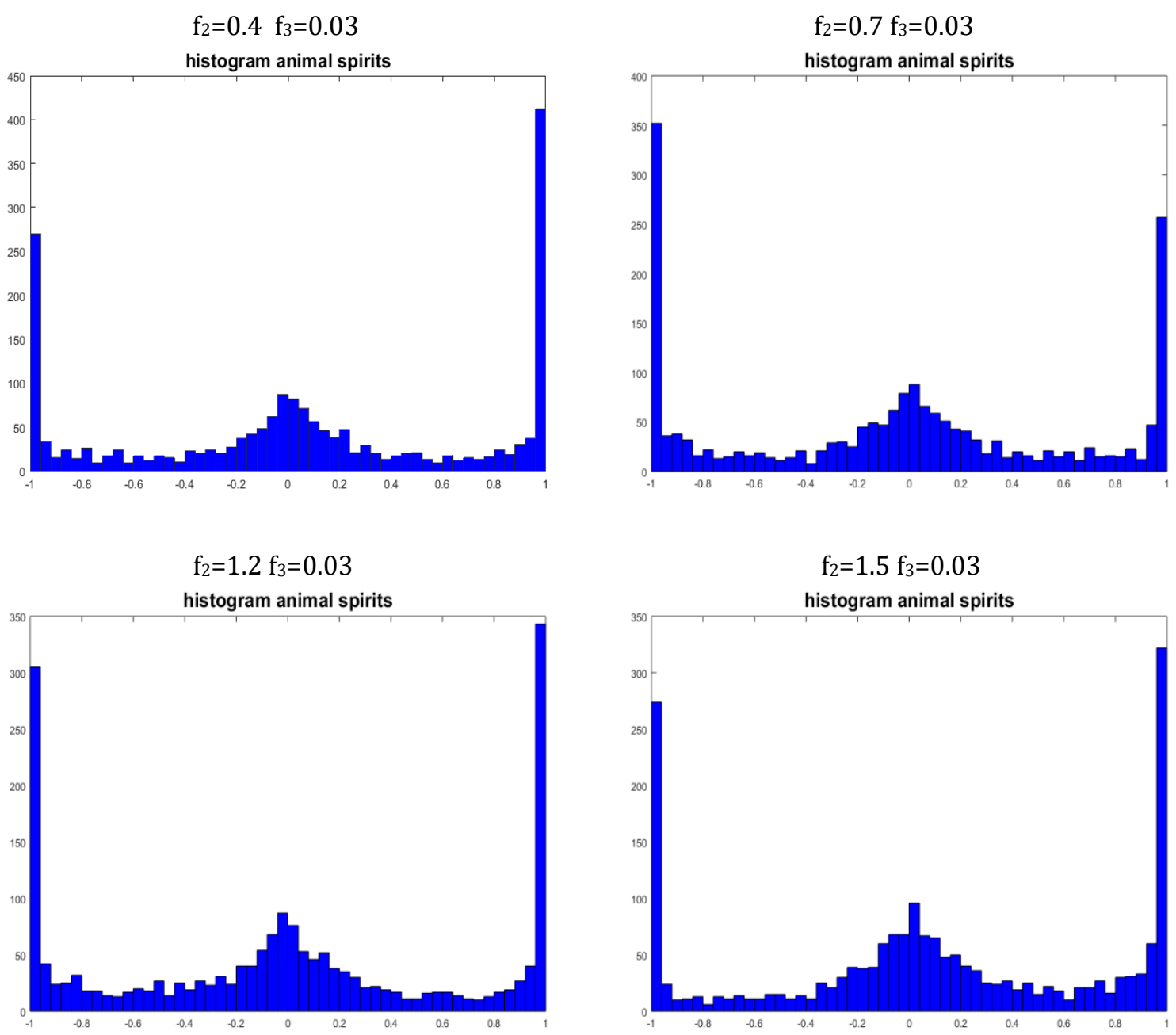
One possible explanation is the fact that the debt constraint reduces the capability of the government to stabilize animal spirits. In order to verify this intuition, we set $f_{3}=0$ (which means excluding the debt constraint from the fiscal policy rule) and re-simulate the model for the different values of $f_{2}$. The results are reported in figure 7 and are quite striking.

Progressively increasing $f_{2}$ now allows the government to reduce the intensity of animal spirits and for sufficiently high values of $f_{2}$ (very strong emphasis on output stabilization) the extreme values in the animal spirits are basically eliminated.

Figure 7: Animal Spirits under Different Output Coefficients in Fiscal Rule [No Debt Stabilization]
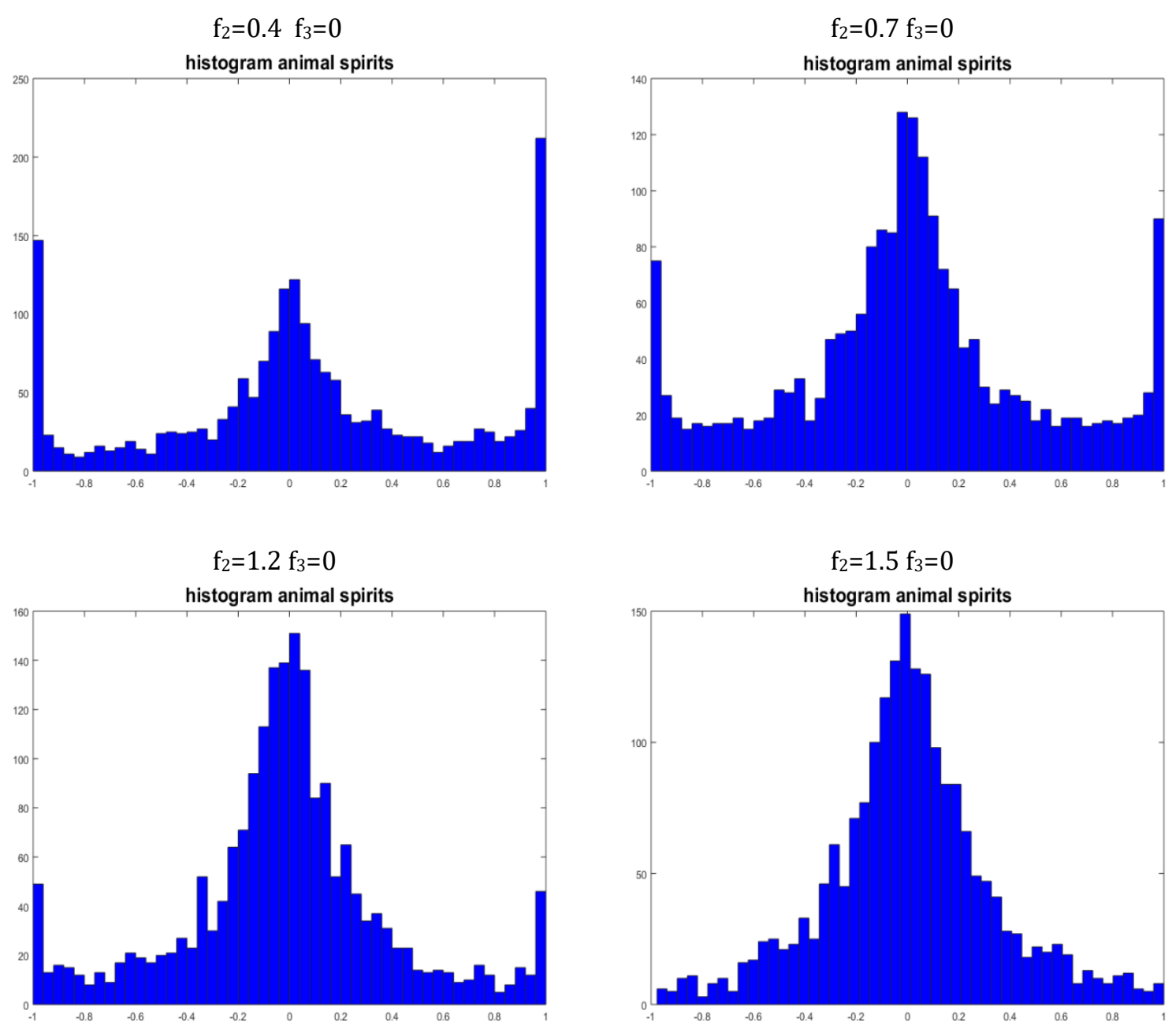
Thus, by combining the evidence from figures 6 and 7, we can conclude that governments face a trade-off between the stabilization of animal spirits and the stabilization of public debt. This is telling us that governments may not be able to stabilize booms and busts due to the debt constraint they face.

To see this more clearly, suppose that an economy experiences a recession produced by a strong wave of pessimism. The recession will lead to an automatic increase in the budget deficit and to an increasing public debt. This leads to a trade-off for the fiscal authorities: attempts at stabilizing output by fiscal stimulus will increase the budget deficit and raise public debt. The same holds when the economy experiences a boom produced by strong optimism. This also implies that there is an opposite movement between animal spirits and public debt. If the government follows a fiscal rule like in equation (4), it will have to choose between the stabilization of the animal spirits and the stabilization of public debt.

To support this point, in figure 8 we compare the pattern of animal spirits with the movements of public debt around its steady state as simulated in our model.

Figure 8: Animal Spirits and Debt

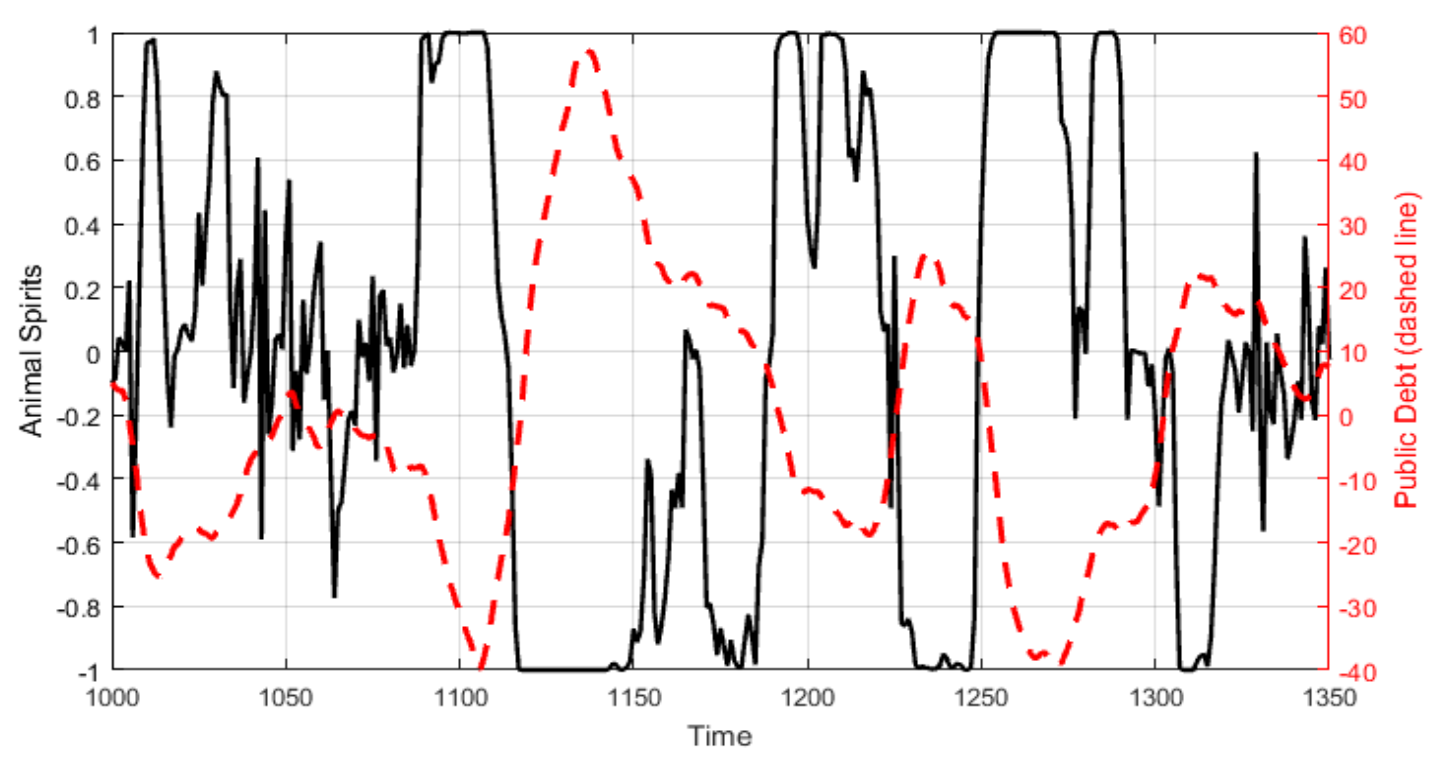

It can easily be seen that the two series move in opposite directions. This implies that periods characterized by high levels of public debt are associated with strong pessimism. Conversely, periods characterized by economic agents' optimism are associated with 
contractions in public debt. We find that the correlation coefficient between animal spirits and public debt in our simulation is equal to -0.75 .

Given the strong co-movements between animal spirits and the output gap, figure 8 suggests that there may also be a trade-off between the stability of output gap and of public debt. We investigate the existence of such a trade-off in the following way. First, the model is simulated 1000 times. Then, we use the average standard deviations of output gap and public debt for different values of the output parameter in the fiscal rule $\left(f_{2}\right)$. The results are represented in figure 9 and 10. Figure 9 shows how output variability changes as $f_{2}$ increases from 0.1 to 2 . Each line represents the outcome for different values of the debt coefficient in the fiscal rule $\left(f_{3}\right)$. Figure 10 follows the same logic but looks at the variability of public debt. Both figures exhibit the expected results.

Figure 9: Output Variability and Output Parameter in Fiscal Rule

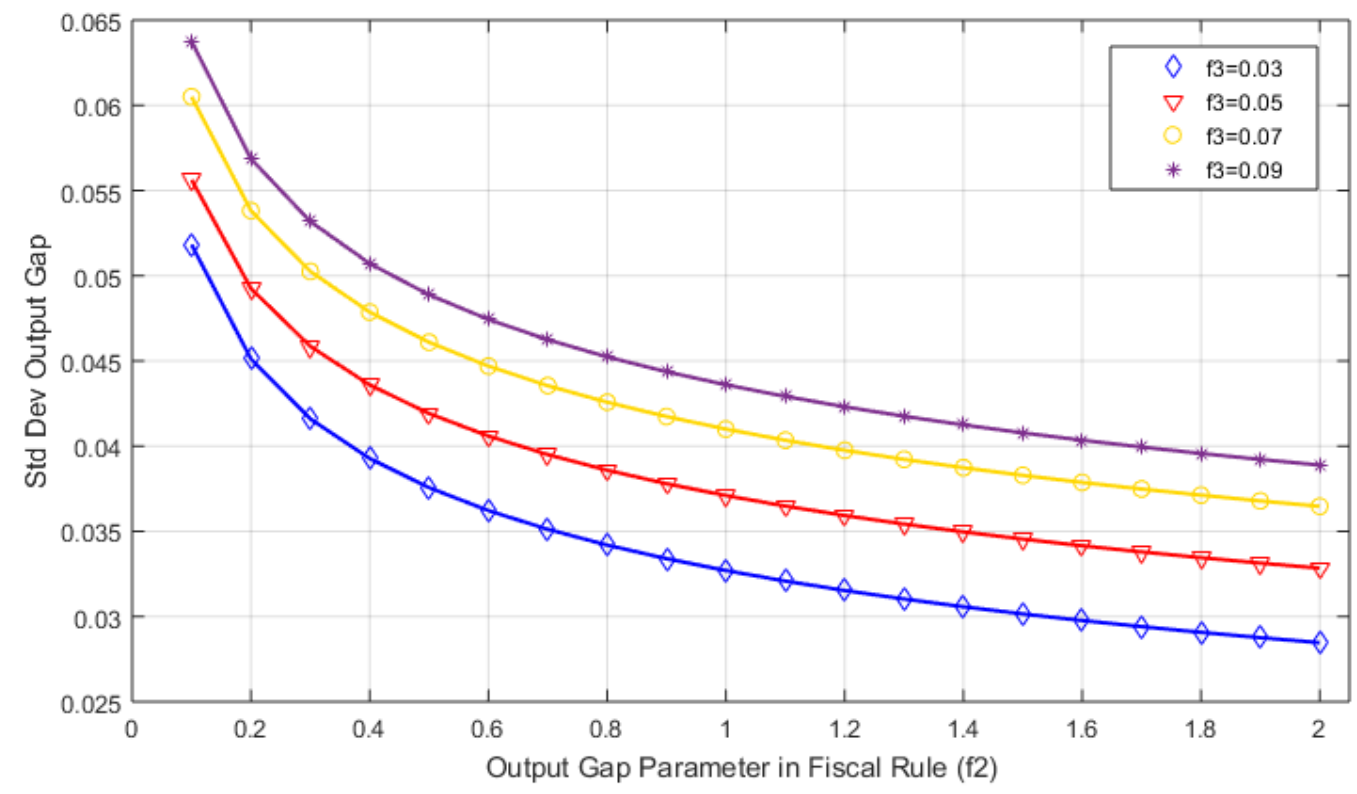

Figure 9 shows that by increasing output stabilization the government reduces output volatility. However, an increasing focus by the fiscal authority on debt stabilization (increasing $f_{3}$ ) implies higher output volatility for any given level of $f_{2}$.

Figure 10 shows that higher values of the output stabilization parameter in the fiscal rule result in higher public debt volatility. We also observe that an increase in $f_{3}$ lowers the debt volatility for any given level of $f_{2}$. 
Figure 10: Debt Variability and Output Parameter in Fiscal Rule

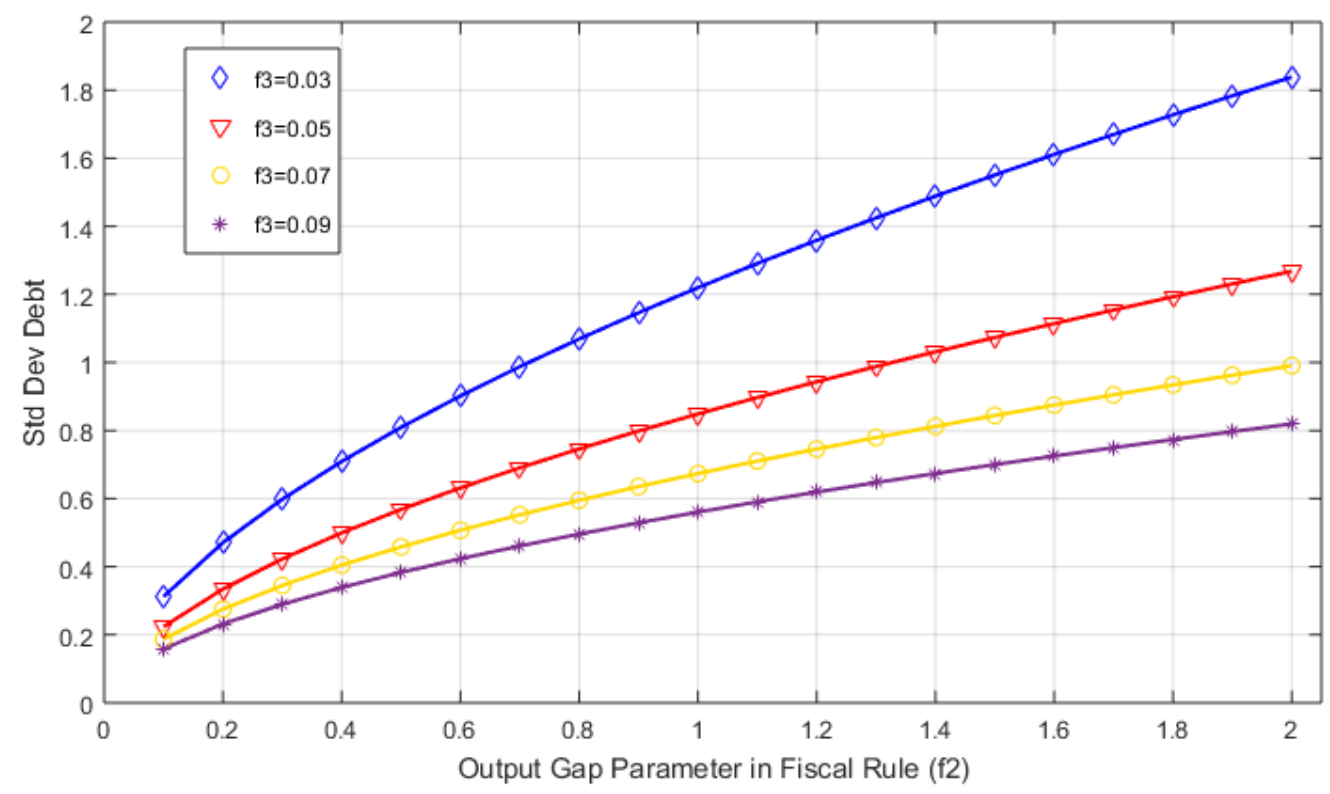

Combining figures 9 and 10, we show the existence of the trade-off between the volatility of the output gap and of public debt in figure 11. The horizontal axis shows the standard deviation of public debt and the vertical axis the standard deviation of the output gap. The downward sloping lines represent the trade-off for different values of $f_{3}$.

Figure 11: Trade-off between Output and Debt Stabilization

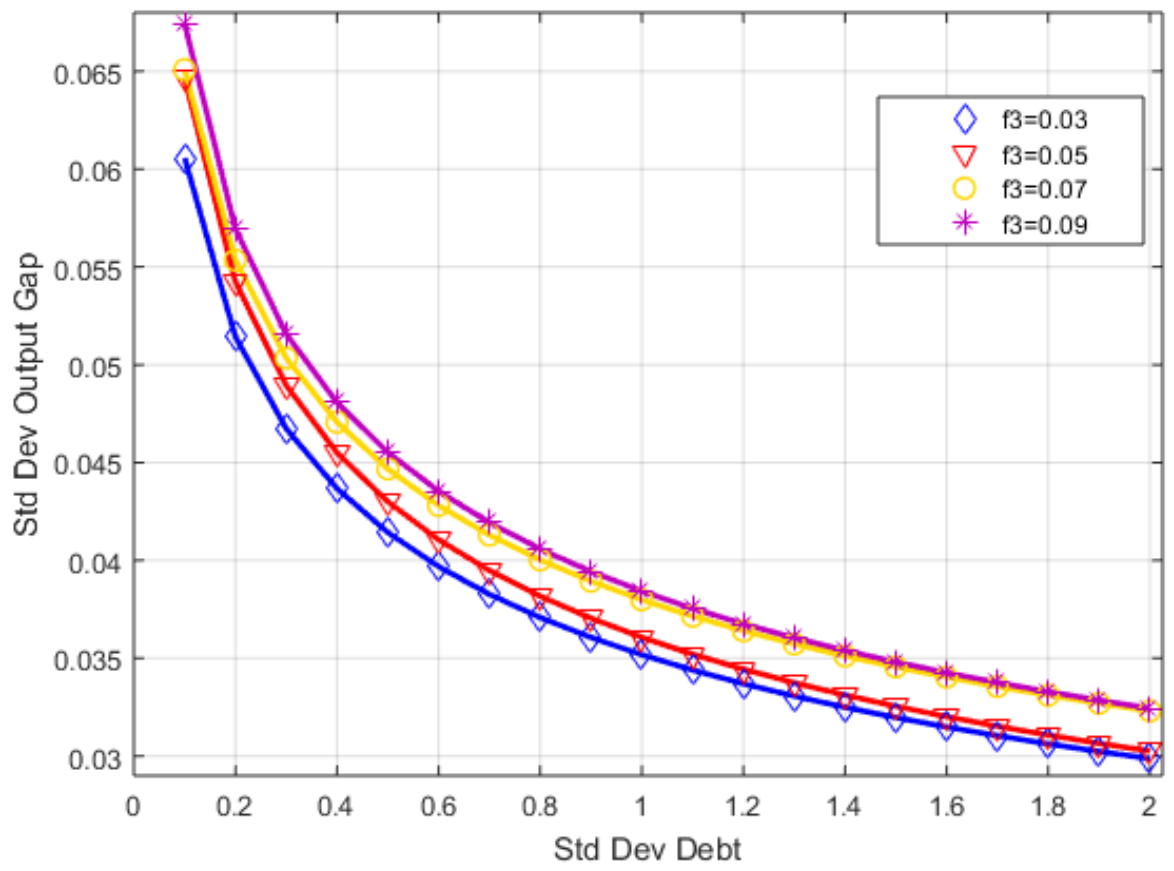


Figure 11 shows how an increase in the stabilization of output comes at a price, i.e. it leads to an increase in the volatility of public debt, and vice versa. This can be seen as follows. Starting from the upper left point on a trade-off line, as $f_{2}$ (the output stabilization parameter) increases, we move downwards along the line, implying that more output stabilization by the government leads to a decline in output volatility at the expense of the stability in public debt.

This result comes from the interaction between animal spirits, the output gap and public debt. Assume, for instance, that the economy experiences a phase of strong pessimism. This will be associated with decreasing output gap and growing public debt. The government is now facing a dilemma: the increasing debt requires a restrictive fiscal policy, while the decline in the output gap should be accompanied by an expansionary fiscal policy. The reaction of the government to such a trade-off will be determined by the parameters in the fiscal rule. Lower values of $f_{2}$ (and higher ones of $f_{3}$ ) imply little effort by the government to stabilize output and allow the fiscal authority to focus on debt stabilization instead. The opposite occurs for higher values of $f_{2}$ and lower values of $f_{3}$.

\section{The Model at the Zero Lower Bound}

Since the financial crisis, the nominal interest rate in many advanced economies has dropped and reached the ZLB. Recent studies have shown that the functioning of a system can be substantially different under this circumstance (see Fernández-Villaverde et al., 2015, Aruoba et al., 2018; Christiano et al., 2011; Woodford, 2011). Thus, as a last step in our analysis, we impose the condition that $r_{t}>0$ and study the functioning of our model when the ZLB binds.

In figure 12, we show the simulated series of output gap, inflation and public debt in the time domain. We plot these series together with the ones representing the time path of animal spirits and of the fraction of inflation extrapolators when the model is calibrated by imposing the ZLB. We keep the assumption that the central bank sets the inflation target at 0 .

The results of the simulation imply that when the ZLB prevails, the economy can be trapped into a deflationary spiral that is dynamically unstable. 
Figure 12: Output, Inflation, Debt and Expectations when the ZLB Prevails

[A]

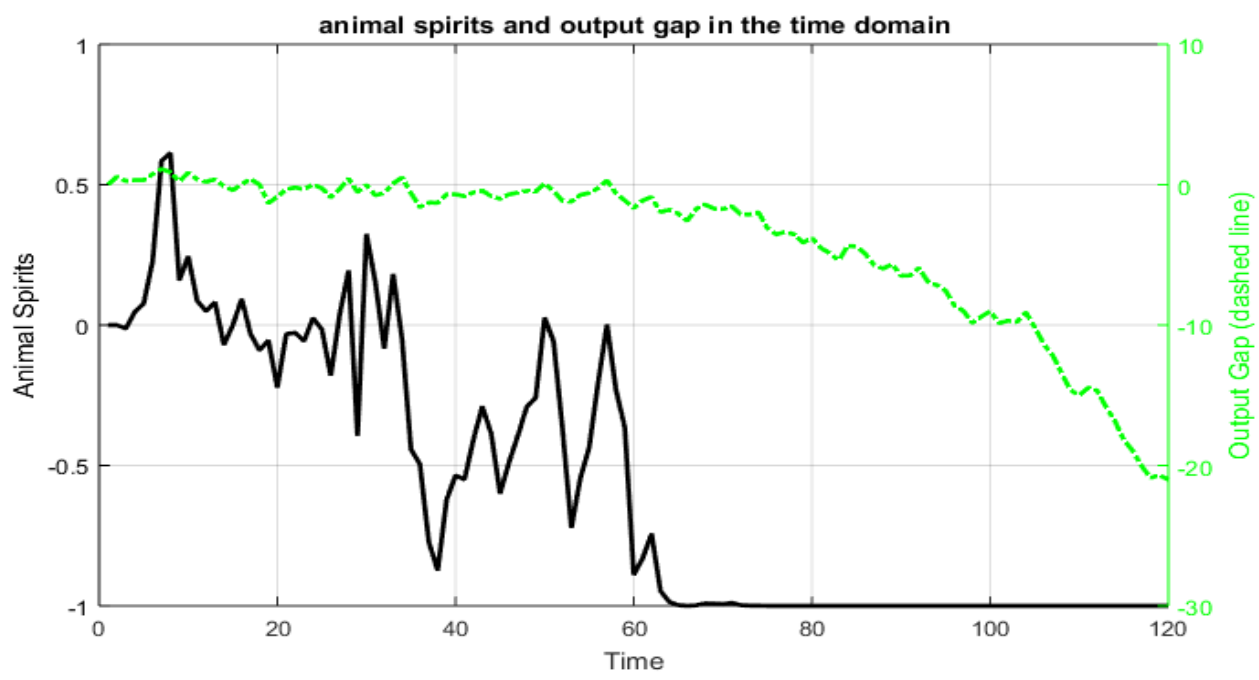

[B]

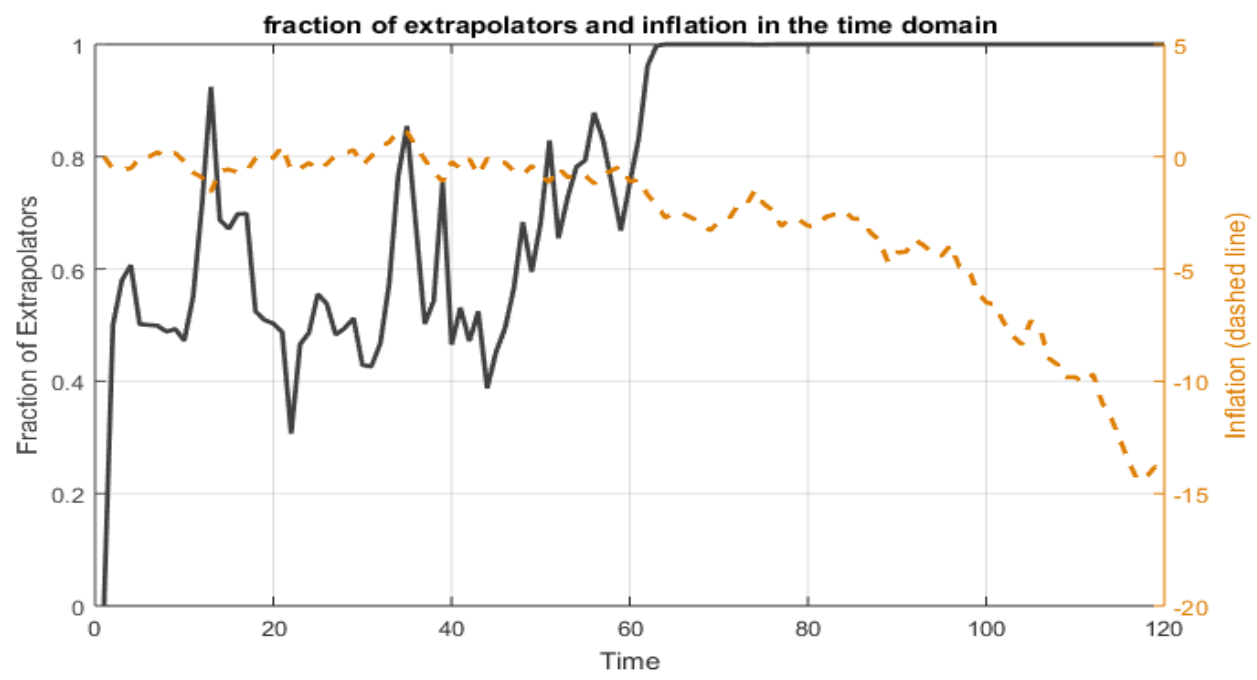

[C]

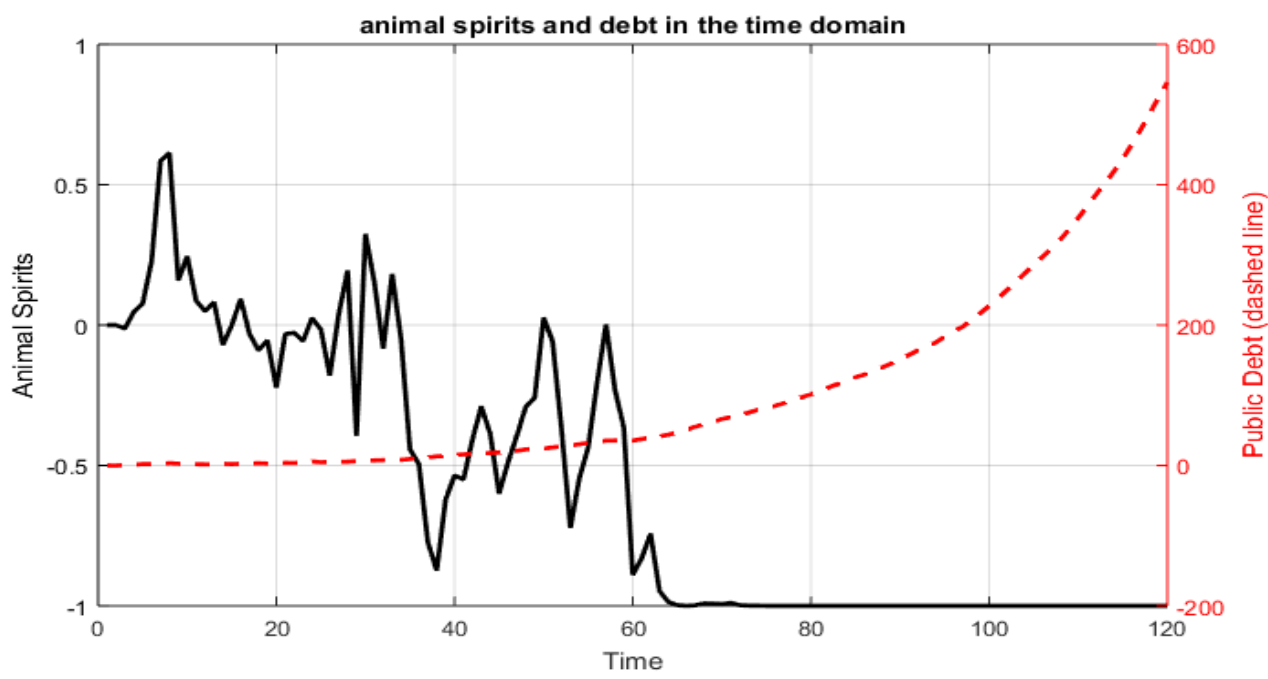


This is confirmed by the simulated series of the output gap (panel A) and inflation (panel B). At the same time, the public debt level explodes (see panel C).

The contrast with the results obtained in the previous sections is strengthened by the series representing the animal spirits and the fraction of inflation extrapolators reported in figure 12. Panel A shows that animal spirits are characterized by extreme pessimism when the ZLB binds and the economy is gripped the deflationary spiral. Furthermore, panel B shows that, once the economy enters the deflationary spiral, extrapolative expectations on inflation prevail as a result of the declining paths in the inflation rate. Thus, agents stop using the central banks' target as a credible reference point. Furthermore, the model shows how the chronic pessimism is also associated with an explosive dynamics of public debt.

According to our model, the inflation target of the central bank plays a crucial role in relation to the ZLB. It can be shown that when the central bank targets a low level of inflation, the chances that the system can hit the ZLB, and enters a deflationary spiral, are substantially higher (see Summers, 1991). We show this in figure 13. The system has been simulated for different values of the inflation target (from 0 to 5\%). For each target, we have run 50 simulations of the model for 130 periods. In panel $A$, the number of times that the system has hit the ZLB are reported. Clearly, progressively increasing the inflation target allows the system to avoid the ZLB. In panel B, we also present the number of times that the system, after hitting the ZLB, has been trapped in the deflationary spiral. Again, we can conclude that higher values of the inflation target imply lower risk of entering a deflationary spiral. From the results in figure 13, we can conclude that an inflation target between $4 \%$ and $5 \%$ should be able to avoid the system entering the unstable deflationary spiral. The interpretation suggested by our model is the following. The lower the inflation target, the more cyclical movements in output gap and animal spirits can lead to recessions that also drive inflation into negative territories. When this happens, the zero bound constraint that applies to the nominal interest rates makes it impossible for the central bank to lower the real interest rate to stimulate the economy. If the recession is deep, and deflation intense, the real interest rate is likely to increase significantly. Thus, the recession becomes protracted and the deflationary spiral is amplified by the growing pessimism. This will then imply the dynamic unsustainability of public debt. 
Based on our results, we can conclude that low levels of inflation target constitute a breeding ground for deflationary spirals ${ }^{11}$.

\section{Figure 13: Inflation Target and the ZLB.}

[A]

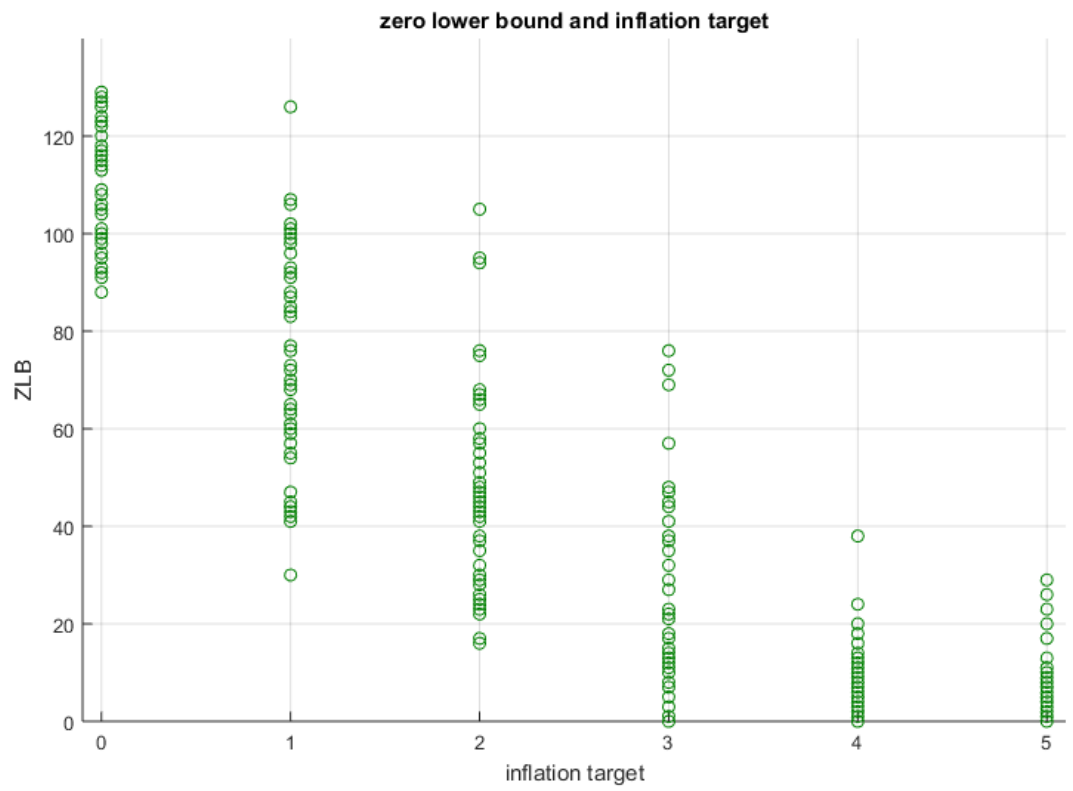

[B]

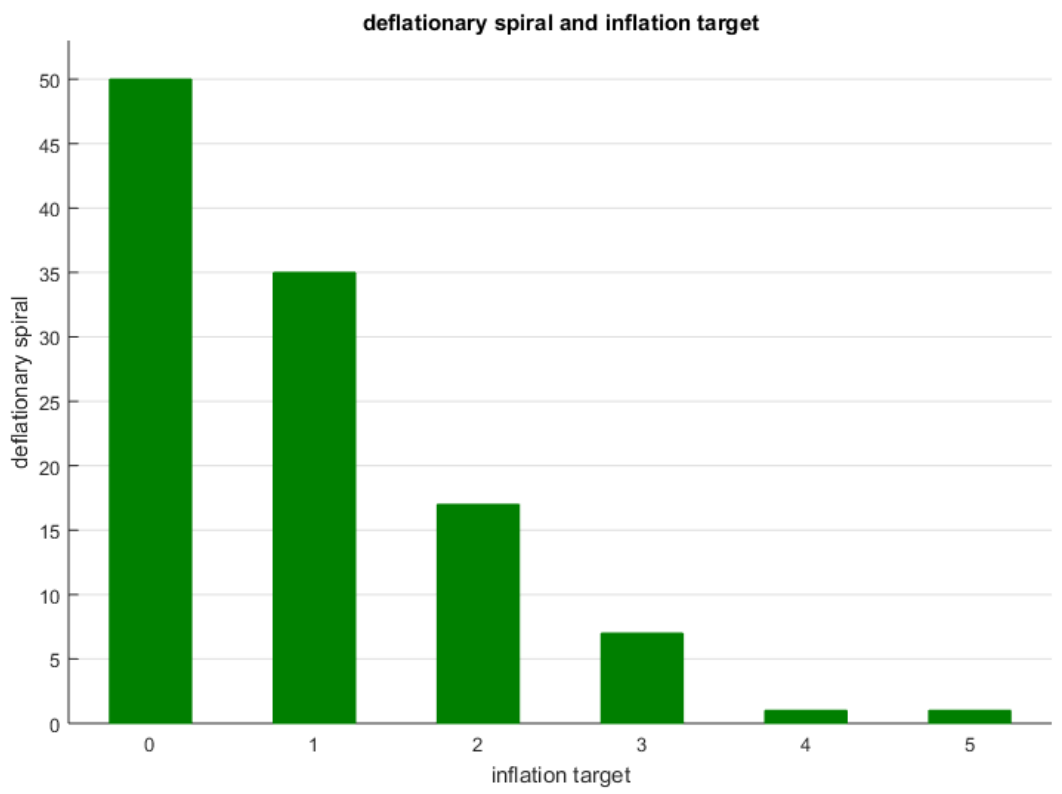

${ }^{11}$ The dynamics of a similar model under different inflation targets when the ZLB prevails is analyzed further in De Grauwe and Ji (2017). 


\section{Conclusion}

In this paper, we have analyzed fiscal policy in the framework of a behavioral macroeconomic model. In order to do so, we have extended the behavioral New Keynesian model of De Grauwe (2011) by adding a fiscal policy block. The model has nonlinear features and due to the agents' cognitive limitations, generates waves of optimism and pessimism (animal spirits). This framework has allowed us to study the effects of government spending by taking into account its interactions with animal spirits, monetary policy and public debt. Our main results can be summarized as follows.

First, our behavioral model shows that the short-run spending multiplier is characterized by substantial volatility and state-dependency. The short-run multiplier depends on the animal spirits and on the state of the business cycle. It is stronger under both extreme optimism and pessimism and reduces in periods of tranquility. One policy implication is that austerity measures in periods of strong economic contraction have a relatively strong negative impact on output.

We have also shown that another source of state-dependency of the multiplier is monetary policy. An active role of the central bank in the stabilization of output reduces the real effects of fiscal policy. The more the monetary authority focuses on output stabilization, the lower the short-run impact of public expenditure on output.

Second, we have found that, under common and reasonable calibrations of the fiscal rule, fiscal policy is not able to reduce the presence of animal spirits even assuming strong focus on output stabilization. To be able to reduce the presence of animal spirits, governments should give up public debt stabilization. This result depends on the fact that periods of increasing public debt are characterized by intense pessimism, while periods of decreasing public debt are characterized by intense optimism. This finding has then led us to show how governments face a trade-off between the stabilization of the output gap and the stabilization of public debt.

Finally, we have analyzed our model when the ZLB on the interest rate prevails. We have shown that, depending on the level of the central bank's inflation target, the economy can be trapped into a deflationary spiral in which the system also experiences chronic pessimism and explosion of public debt. 


\section{References}

Anderson, S., de Palma, A. and Thisse, J.F. (1992), "Discrete Choice Theory of Product Differentiation", MIT Press, Cambridge, Mass.

Auerbach, A. and Gorodnichenko, Y. (2012), "Measuring the Output Responses to Fiscal Policy." American Economic Journal: Economic Policy, 4(2), pp. 1-27.

Auroba, S.B., Cuba-Borda, P. and Schorfheide, F. (2018), "Macroeconomic Dynamics Near the ZLB: A Tale of Two Countries”, Review of Economic Studies, 85, pp. 87-118.

Branch, W.A. (2004), “The Theory of Rationally Heterogeneous Expectations: Evidence from Survey Data on Inflation Expectations”, Economic Journal, 114(497), pp. 592-621.

Brock, W. and Hommes, C. (1997), "A Rational Route to Randomness", Econometrica, Econometric Society, 65(5), pp. 1059-96, September.

Brock W. and Hommes C. (1998), "Heterogeneous Beliefs and Routes to Chaos in a Simple Asset Pricing Model”, Journal of Economic Dynamics and Control, 22(8-9), pp. 1235-74.

Carroll, C.D. (2003), "Macroeconomic Expectations of Households and Professional Forecasters", Quarterly Journal of Economics, 118(1), pp. 269-298.

Caprioli, F. (2015), "Optimal Fiscal Policy under Learning", Journal of Economic Dynamics and Control, Elsevier, 58(C), pp. 101-124.

Christiano, L., Eichenbaum, M. and Rebelo, S. (2011), "When Is the Government Spending Multiplier Large?”, Journal of Political Economy, 119(1), pp. 78-121.

De Grauwe, P. (2011), “Animal Spirits and Monetary Policy”, Economic Theory, 47(2-3), pp. 423-57.

De Grauwe, P. (2012), "Lectures on Behavioral Macroeconomics”, Princeton University Press.

De Grauwe, P. and Ji, Y. (2017), "Inflation Targets and the Zero Lower Bound in a Behavioral Macroeconomic Model”, Economica, doi:10.1111/ecca.12261.

Driscoll, J.C. and Holden, S. (2014), "Behavioral Economics and Macroeconomic Models", Journal of Macroeconomics, Elsevier, 41(C), pp. 133-147.

Evans, G.W., Honkapohja, S. and Mitra, S. (2009), “Anticipated Fiscal Policy and Adaptive Learning”, Journal of Monetary Economics, 56(7), pp. 930-953.

Evans, G.W., Honkapohja, S. and Mitra, S. (2012), "Does Ricardian Equivalence Hold When Expectations Are Not Rational?”, Journal of Money, Credit and Banking, 44(7), pp.12591283.

Fernández-Villaverde, J., Gordon, G., Guerrón-Quintana, P. and Rubio-Ramírez, J. (2015), "Nonlinear Adventures at the Zero Lower Bound", Journal of Economic Dynamics and Control, 57(C), pp. 182-204. 
Ferrero, A. (2009), "Fiscal and Monetary Rules for a Currency Union", Journal of International Economics, Elsevier, 77, pp. 1-10.

Frenkel, J and Froot, K. (1987), "Using Survey Data to Test Standard Propositions Regarding Exchange Rate Expectations”, American Economic Review, 77(1), pp. 133-153.

Frenkel, J and Froot, K. (1988), "Chartists, Fundamentalists, and Trading in the Foreign Exchange Market”, American Economic Review, 80(2), pp. 181-185.

Gabaix, X. (2016), "A Behavioral New Keynesian Model", CEPR Discussion Papers 11729, C.E.P.R. Discussion Papers.

Galí, J. (2008), “Monetary Policy, Inflation and the Business Cycle”, Princeton University Press.

Galí, J. and Monacelli, T. (2005), "Monetary Policy and Exchange Rate Volatility in a Small Open Economy". Review of Economic Studies 72 (3), pp. 707-734.

Galí, J. and Monacelli, T. (2008), "Optimal Monetary and Fiscal Policy in a Currency Union", Journal of International Economics, Elsevier, 76(1), pp. 116-32, September.

Gasteiger, E. and Shoujian, Z. (2014), "Anticipation, Learning and Welfare: The Case of Distortionary Taxation", Journal of Economic Dynamics and Control, Elsevier, 39(C), pp. 113-126.

Hommes, C. (2011), "The Heterogeneous Expectations Hypothesis: Some Evidence from the Lab", Journal of Economic Dynamics and Control, Elsevier, 35(1), pp. 1-24.

Kirsanova, T., Satchi, M., Vines, D. and Wren-Lewis, S. (2007). "Optimal Fiscal Policy Rules in a Monetary Union," Journal of Money, Credit and Banking, Blackwell Publishing, 39(7), pp. 1759-84, October.

Kirsanova, T., Stehn, S.J. and Vines, D. (2005), "The Interactions between Fiscal Policy and Monetary Policy", Oxford Review of Economic Policy, 21(4), Fiscal Policy (Winter), pp. 532-64.

Kirsanova, T. and Wren-Lewis, S. (2012). "Optimal Fiscal Feedback on Debt in an Economy with Nominal Rigidities", Economic Journal, Royal Economic Society, 122(559), pp. 238-64.

Manski, C.F. and McFadden, D.L. (1981). "Alternative Estimators and Sample Designs for Discrete Choice Analysis”. In Manski, C.F. and McFadden, D.L. (Eds.), Structural Analysis of Discrete Data and Econometric Applications. The MIT Press, Cambridge.

Monacelli, T. and Perotti, R. (2008), "Fiscal Policy, Wealth Effects and Markups", CEPR Discussion Papers 7099, C.E.P.R. Discussion Papers.

Muscatelli V.A. and Tirelli, P. (2005), "Analyzing the Interaction of Monetary and Fiscal Policy: Does Fiscal Policy Play a Valuable Role in Stabilisation?", CESifo Economic Studies, CESifo, 51(4), pp. 549-85. 
Parker, J.A. (2011), “On Measuring the Effects of Fiscal Policy in Recessions”, Journal of Economic Literature, 49(3), pp. 703-718.

Pfajfar, D. and Santoro, E. (2010), "Heterogeneity, Learning and Information Stickiness in Inflation Expectations”, Journal of Economic Behaviour and Organization, 75(3), pp. 426444.

Ravn, M., Schmitt-Grohé, S. and Uribe, M. (2006), "Deep Habits", Review of Economic Studies, Oxford University Press, vol. 73(1), pp. 195-218.

Summers, L., (1991). "Panel Discussion: How Should Long-Term Monetary Policy Be Determined?", Journal of Money, Credit, and Banking, 23(3, Pt 2), pp. 625-631.

Woodford, M. (2011), "Simple Analytics of the Government Expenditure Multiplier", American Economic Journal: Macroeconomics, 3(1), pp. 1-35. 